\title{
15
}

\section{Phase 5: Retreating Forests, Flat- Bottomed Ditches and Raised Fields}

\author{
Tim Bayliss-Smith, Jack Golson and Philip Hughes
}

\section{Introduction}

\section{Before Phase 5}

The reasons for abandonment of Kuk Swamp and other Wahgi wetlands around the time that Olgaboli (Q) Tephra fell were discussed in the previous chapter. In the short term, the effects of the tephra fall were no doubt damaging to crops, and in indirect ways the event may have caused some disruption to the political stability and social bonds that underpinned the wetland drainage efforts of Phase 4. It is also likely that Olgaboli Tephra provided a temporary fertility boost to dryland agriculture. However, we cannot be sure about the extent to which the marked and sustained increase in Casuarina in the pollen record after the fall of Olgaboli registers the initiation of tree fallows for soil regeneration, as once proposed, rather than tree planting for timber production in circumstances of deforestation (see Chapter 14, section 'Dryland agriculture after Phase 4'). For whatever combination of reasons, the fall of Olgaboli Tephra saw the beginning of a long period of disuse of Kuk Swamp for gardening.

Dryland cultivation at this time probably involved almost all of today's crops with the obvious and major exception of the sweet potato. In the Wahgi grasslands, we can reconstruct an agricultural system based on soil tillage for bananas and yams, together almost certainly with sugarcane and possibly winged bean (Psophocarpus tetragonolobus). It seems likely that some taro was still being cultivated on small patches of enriched soils, but we believe that taro's importance had declined because in the largely deforested landscapes of the upper Wahgi Valley, all dryland sites and drained wetlands would have experienced major damage to taro corms from Papuana beetles (see Chapter 14, sections 'Taro in the wetlands' and 'Fields and fallows').

Pigs were certainly present in late Phase 5 (as discussed below), though possibly only in small numbers. Exchange systems would have involved a range of valued commodities other than pigs, but of these the stone-axe trade is almost the only form of exchange with some potential for being registered in the archaeological record. The distribution of high-grade stone from quarries in the Wahgi and Jimi Valleys is a useful indicator of the growth and spread of regional exchange systems (Burton 1984, 1989; see Chapter 21, section 'Ground axes and axe quarries'). The indications are that such growth and spread had already begun in Phase 4 times, though the proposition is in need of support at additional stratified sites in the region (see Chapter 14, section 'Kuk as a Phase 4 "hotspot"?'). 


\section{Dating the onset of Phase 5}

Phase 5 of drainage started at some point after the fall of Olgaboli (Q) Tephra between AD 720 and 980 (Table 7.2, citing Haberle 1998a) and before that of Kenta (Sandy 1) tephra, an ash that is not often preserved at Kuk and has not been dated there. The phase ends with another tephra fall, that of Tibito $(Z)$, and there are two radiocarbon dates from below this ash that relate to the operation of the Phase 5 system. Charcoal low in the fill of a Phase 5 ditch and wood from the older phase of a recut Phase 5 ditch are highly likely to date between AD 1310 and 1620 in the first case and $\mathrm{AD} 1430$ and 1650 in the second. ${ }^{1}$ The second age range applies also to a wooden paddleshaped spade found close to the dated wood in the older phase of the ditch, as discussed below.

Dates for Phase 5 were subsequently obtained for another Wahgi Valley swamp site, Kana, near Minj, where Tibito Tephra and Olgaboli Tephra were both present, but not Kenta tephra. The dates caused some difficulties. Bark from the base of a ditch typologically and stratigraphically equivalent to Kuk Phase 5 gave a date within the range AD 980-1410. On the other hand, a digging stick from a similar ditch at the site at first gave an unacceptably old age. Then, after treatment for possible contamination, a result within a date range from $\mathrm{AD} 1430-1660,{ }^{2}$ almost identical with that for Phase 5 wood from Kuk discussed above.

In order to judge whether Phase 5 is likely to have begun as early as between AD 980 and 1410, as suggested by the bark result at Kana, we look at evidence relevant to the date of the fall of Kenta tephra, by which time Phase 5 was underway at Kuk. The evidence in question comes from site MSI at Yeni Swamp on the Ruti Flats some $50 \mathrm{~km}$ north of Kuk at about 500 m altitude (Gillieson, Gorecki and Hope 1985: Fig. 4; Gillieson, Hope and Luly 1989: 108-116, Fig. 6.3). There are two bands of tephra in sedge peat above a carbonised wood layer $1 \mathrm{~m}$ below the swamp surface. The age of this wood layer lies between AD 1020 and 1260, somewhat younger than Olgaboli (Q) Tephra, so indicating that the upper ash is Tibito (Z) Tephra and the lower one Kenta (Sandy 1) tephra. A radiocarbon date for peat lying on top of Kenta tephra at the site gives a terminal date for the ashfall within a calibrated age range between $\mathrm{AD} 1270$ and 1640 (Table 7.2, ANU-3909). Assuming an even rate of peat growth over the roughly $0.6 \mathrm{~m}$ separating the layer of carbonised wood dated between AD 1020 and 1260 and Tibito Tephra dated possibly to the AD 1660s (Table 7.2, and discussed below), Kenta tephra, about halfway between the two, would have a date within an approximate range from AD 1340 to 1460.

Comparing the calculated estimate for Kenta tephra's deposition of between AD 1340 and 1460 with the date ranges for the four Phase 5 garden ditches that we have discussed, we can say with some confidence that two of these, one at Kuk (AD 1430-1650) and one at Kana (AD 14301660), cannot belong to the pre-Kenta stage of Phase 5 because they are too young. The same is likely to be true for the second Kuk ditch (AD 1310-1620). On the other hand, the date range of the bark from the second Kana ditch, AD 980-1410, starts appreciably earlier than those of the three other ditch features and also that of Kenta tephra. We propose that, as represented by the bark date of the second Kana ditch, Phase 5 began at some point within the age range AD 980-1410. For reasons that are set out in the next section, we favour a starting date for Phase 5 of around AD 1250 , in other words within the third quartile (about $\mathrm{AD} 1200-1300$ ) of the date range for the Kana ditch. This date would give Phase 5 a total duration of about 400 years before a terminal date possibly in the $\mathrm{AD} 1660 \mathrm{~s}$. This duration for the phase would be consistent with the archaeological evidence from Kuk that at least three subphases occurred within it.

1 Calibration of the charcoal date, ANU-1055, 480 \pm 60 BP, and of the wood date (Golson and Steensberg 1985: 375-376), K-2643, 370 \pm 70 BP, both at two standard deviations, BP = Before Present, which is AD 1950 by radiocarbon convention.

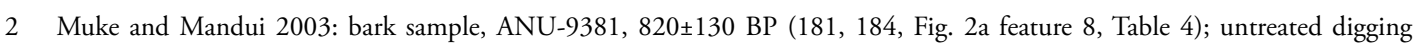
stick, ANU-10964, 1520 150 BP (184, Table 4); digging stick after treatment, (184, Table 4). All dates calibrated at two standard deviations. 


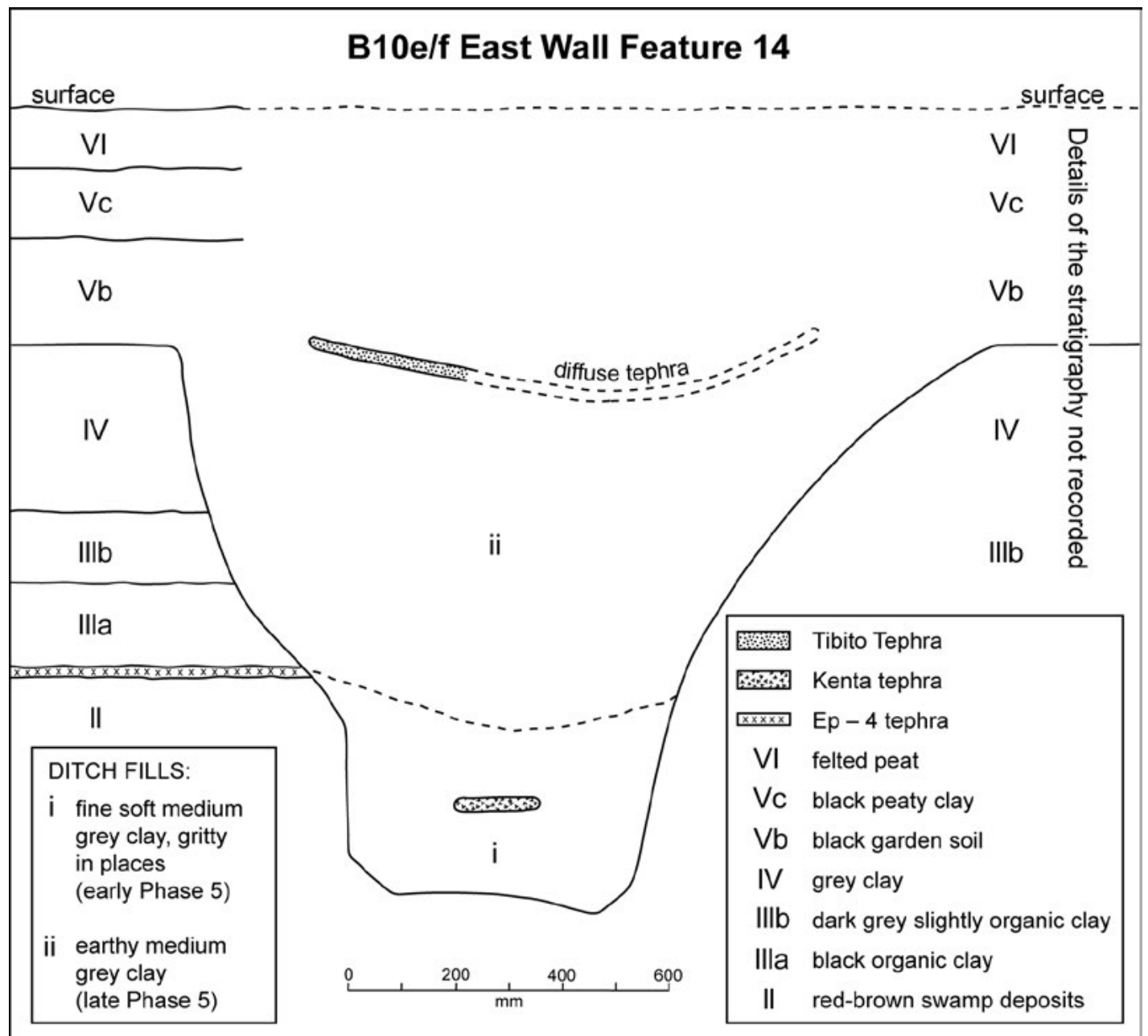

Figure 15.1 Cross-section of a composite ditch exposed in the east wall of drain B10e/f.

Kenta tephra marks an early stage of ditching, followed by recutting to a wider and shallower ditch form whose fill is sealed by Tibito Tephra. The ash signals the end of Phase 5.

Source: Drawing by Philip Stickler, after a field drawing of 1974 in the Kuk archive.

Kenta tephra is of rare occurrence at Kuk and cannot often be found in ditch cross-sections, in contrast to the later Tibito Tephra. Nevertheless, the circumstances of its appearance lend support to the case we are arguing for a beginning of Phase 5 around AD 1250. As an example, we reproduce the cross-section of a ditch in the east wall of drain B10e/f about $70 \mathrm{~m}$ from its northern end (Fig. 15.1). Kenta tephra belongs to a very early subphase of the structure, whereas Tibito Tephra seals in its final subphase. The cross-section of the ditch in the west wall of the drain shows a profile that suggests a more complex history than that revealed by its partner in the east wall (cf. the profile of Korowa's Baret in Fig. 16.6).

\section{The wider context of mediaeval warming}

Even though there is only one reliable radiocarbon date for the onset of Phase 5 (ANU-9381, from Kana) and this converts to a wide age range, AD 980-1410, we think that there are good arguments to support a likely date around AD 1250 for the beginning of this phase. We argued in Chapter 14 that Phase 4 began in the context of severe El Niño-Southern Oscillation (ENSO) droughts that were experienced in New Guinea during the period between 2500 and 1700 years ago (Gagan et al. 2004; McGregor and Gagan 2004). It was this crisis, we suggested, that 
provided the incentive and the opportunity for large-scale wetland drainage. Simon Haberle (1998a: 9) has proposed that this disturbed period of intensified ENSO was followed in New Guinea by warmer and more stable conditions that correspond to the northern hemisphere's Mediaeval Warm Period (MWP) or Little Climate Optimum (LCO). The MWP/LCO (called MWP from here on) is now interpreted by many climatologists as a global phenomenon with regional variations that affected climates during the period from about AD 950 to 1250 (Mann et al. 2009: 1257), reaching peaks at about AD 1000 and again at AD 1100 (Moberg et al. 2005: 616). It may be no coincidence that at Kuk these MWP peak temperatures fall within the interval between Phase 4 and Phase 5, when no swamp agriculture took place at Kuk (Chapter 14, section 'Responses to drought', citing Haberle 1998a and Haberle and David 2004).

It is generally agreed that the MWP was followed by a global change towards cooler and more unstable climates, culminating in the Little Ice Age (LIA) of AD 1400-1700 (Wanner et al. 2008; Mann et al. 2009). In New Guinea the effects of these changes were too subtle to be reflected in lake sediments or the pollen record, where the anthropogenic signal is dominant. However, we can find evidence in changing sea-surface temperatures as reconstructed from marine sediments in the Makassar Strait between Kalimantan and Sulawesi in Indonesia (Oppo, Rosenthal and Linsley 2009). Between AD 1000 and 1250, during a period corresponding to the MWP, seasurface temperatures were close to modern values, but they fell rapidly after that date and from $\mathrm{AD} 1550$ to 1850 were up to $1^{\circ} \mathrm{C}$ cooler than today. The change is linked to a weakening in the summer monsoon after $\mathrm{AD} 1250$, signalling the end of a period of stable, warm and wet conditions in eastern Indonesia and a shift towards more frequent droughts.

Providing a date for this climatic shift in the New Guinea highlands, therefore, requires that we extrapolate from reconstructed events elsewhere in the region. The validity of this extrapolation depends on the assumption that strong regional and global teleconnections make climatic events more or less synchronous in different regions. If we adopt these assumptions, then we may estimate a date for the end of the MWP in New Guinea and the onset of less stable conditions, a transition that elsewhere took place in the period AD 1250-1300. For example, a warmer period ended in the South Island of New Zealand about AD 1280, in Patagonia around AD 1250 and in central Chile around AD 1260; the South American summer monsoon intensified dramatically about AD 1300 in northern Peru, about AD 1250 in southern Ecuador and about AD 1290 in Panama; and there was a shift towards more El Niños in the Galapagos Islands around AD 1250 (Cook, Palmer and D'Arrigo 2002; Villalba 1994; Moy et al. 2002; Lachniet et al. 2004; Conroy et al. 2008; Bird et al. 2011). Patrick Nunn chose the year AD 1300 as marking the climatic shift that generated big changes in the Pacific islands, mainly through increased storminess and sea level fall as the Little Ice Age approached (Nunn 2000, 2007; Nunn and Britton 2001), but he now regards this 'event' as spanning the period AD 1250-1300 (Nunn and Hunter-Anderson 2011: 95). One of the largest volcanic eruptions of the entire Holocene took place in AD 1257 from Samalas volcano on Lombok Island, Indonesia, and is thought to have triggered a moderate to strong El Nińo event and to have had global effects including famines in Europe in 1258 (Oppenheimer 2003; Emile-Geay et al. 2008; Miller et al. 2012; Lavigne et al. 2013; Sigl et al. 2014).

While direct evidence from New Guinea cannot at present confirm the nature and timing of the MWP-LIA shift, from our knowledge of the wider picture it seems highly probable that there was a transition around AD 1250 or soon afterwards towards less stable and somewhat cooler conditions with more frequent droughts. As in the case of the extreme ENSO events that, we believe, initiated Phase 4 around 2000 years ago, we suggest that Phase 5 at Kuk began at this time of climatic transition. 


\section{The end of Phase 5}

As with Phase 4, a tephra fall provides a convenient chronological marker for the end of Phase 5 drainage activity, although in this case the hiatus between Phase 5 and Phase 6 was of brief duration. The volcanic ash, known as Tibito Tephra, was found so close to the base of some ditches as to make it clear that they were open and in principle operational at the time of its fall. This tephra has been the subject of discussion in two earlier chapters of this volume as to its age, extent, effects and source (Chapters 7 and 8). It derived from a cataclysmic eruption of Long Island off the northern coast of New Guinea and was deposited across a conservatively estimated $84,000 \mathrm{~km}^{2}$ of mainland New Guinea (Fig. 8.2), being sporadically preserved in accretionary environments like Kuk Swamp where it can be present in bands up to $50 \mathrm{~mm}$ thick.

The fall of Tibito Tephra is remembered in highlands legends as the Time of Darkness (Blong 1982). In Chapter 8 of this volume, Blong summarises more recent evidence bearing on its age, including radiocarbon dates and their calibrations. He confirms that Tibito Tephra originated from a Long Island eruption, one ranked by Briffa et al. (1998) as within the top 10 most extreme volcanic events occurring worldwide in the past 600 years. All 10 eruptions produced sulphuric aerosols affecting the stratosphere, and in most cases global temperatures were reduced for one or two years. The evidence for this effect comes from the coniferous forests of the northern hemisphere where a narrowing in the tree rings of pines, firs and spruces suggests that the growth of trees was affected by lower temperatures (Briffa et al. 1998).

There are drops in temperature shown in northern hemisphere tree rings dated to AD 1666/67 and 1675 that cannot be clearly assigned to any particular volcano. Can either event be the result of Long Island's eruption? Briffa et al. (1998: 453) suggested that one or other of these tree-ring anomalies might provide 'possible evidence of this eruption'. In a previous publication, we have favoured AD 1665 or 1666 as the likely date for Tibito Tephra (Bayliss-Smith et al. 2005: 110), but in the context of continuing uncertainty have chosen to talk about it as an event of the AD 1660s. Whatever its precise date, this tephra deposit brought Phase 5 at Kuk to an end by disrupting drainage and gardening, though at the same time dryland agriculture probably benefited from the fertilising effects of the ashfall.

\section{Evidence}

\section{The regional geography of Phase 5}

Besides being widespread across Kuk Swamp, Phase 5 has been identified at scattered localities through the upper Wahgi Valley: at Kana near Minj (as discussed above); at Kotna north of the river closer to Kuk; and at the Manton site on Warrawau Tea Estate across the Wahgi river south of Kuk (Golson 1982: 121; Muke and Mandui 2003). Further afield its equivalent is present at Mogoropugua and Haeapugua Swamps in Southern Highlands Province (Ballard 1995: 191195; 2001).

Because Phase 6-the phase that is contemporary with the sweet potato-involved a retreat of cultivation from the deeper swamp to its margins at Kuk and was not explicitly noted at the upper Wahgi sites mentioned in connection with Phase 5, it may well be that the widespread systems of former drainage that are visible from the air largely represent Phase 5 cultivation. If this were the case, it would explain the lack of tradition regarding large-scale drainage among the older inhabitants of the upper Wahgi, who were systematically canvassed on the matter during the 1972 and 1973 fieldwork seasons (Ian Hughes, pers. comm., cited by Golson 1977a: 628). ${ }^{3}$

3 Nine maps used by Ian Hughes when interviewing in the upper Wahgi have been copied by the Pacific Manuscripts Bureau so that they can be accessed by other researchers. 
This supports the evidence of early European explorers like Mick Leahy and Jim Taylor, who did not report seeing signs of such drainage in 1933, when Leahy first visited the North Wahgi and Kuk Swamps, and Taylor the swamp at the future Warrawau Tea Estate (Golson 1976: 216; see Chapter 23, section 'The prelude'). On the other hand, the missionary Vicedom, based in the 1930s at Ogelbeng on what Blong (1986a: 288) calls the southeastern apron of the Mt Hagen volcano, makes reference to cultivation in the swampy upper Wahgi Valley below it, with the use of deep ditching around gardens (Vicedom and Tischner 1943-48: 185; 1983: 209). We discuss this question specifically for Kuk later in the chapter.

The pollen evidence for vegetation changes suggests strongly that dryland sites were also impacted by agriculture before and during Phase 5 (cf. Chapter 9, section 'Mid to late Holocene'). Simon Haberle (1998a: 8) identifies two periods of what he calls 'intensified agricultural activity' in the upper Waghi Valley and its catchments. The first is accompanied by an increase in Casuarina pollen beginning in the period between AD 760 and 980, after the end of Phase 4. There is archaeological evidence from the Etpiti rockshelter $(2200 \mathrm{~m})$ in the Manim Valley (Christensen 1975: 31, 34; Donoghue 1988: 93), which we believe can be read as confirming this trend. The change in cultural material and sedimentation rate about 1100 years ago suggests either horticultural activities on the mountain slopes near the site or possibly an increased use of bush shelters by people seeking greater access to montane forest resources. According to Haberle, the second period of intensified dryland activity begins up to 300 years before the fall of Tibito Tephra, when there was 'a further reduction in forest cover, an increase in Casuarina planting, and an increase in soil erosion' between AD 1300 and 1550 (Haberle 1998a: 8).

In Southern Highlands Province, Chris Ballard's (2001: 296) investigations resulted in dates that broadly match this chronology, but here the archaeological evidence for intensification relates to the use of wetlands. There was gardening along the wetland margins at Haeapugua Swamp between about 1300 and 1000 years ago and again from 600 to 200 years ago.

\section{The archaeological evidence from Kuk}

Following on earlier overviews of Phase 5 (Golson 1976, 1977a), the evidence from Kuk has now been analysed in detail in three areas (Fig. 15.2). They represent the swamp margins (most of block A9), areas of intermediate drainage difficulty (most of blocks A10 and A11) and the more problematic low-lying centre of the swamp (block C9). In these sample blocks, a detailed analysis of the ditch networks and morphology has been carried out, as well as an analysis of the major disposal channels (Bayliss-Smith et al. 2005). The following account is primarily based on this work.

As with Phase 4, the evidence points to a highly organised system of drainage constructed around a hierarchy of ditches consisting of a major disposal channel, called Wai's Baret, minor disposal channels that were tributaries to Wai's Baret, and numerous field ditches joining each other at right angles to define garden areas. In terms of hydrology it is a system very similar to Phase 4, but the field ditches in particular have a shape and depth that immediately differentiate them from their Phase 4 predecessors. Phase 5 is therefore distinctive on the basis of ditch morphology and ditch fill, compacted earth as against silty clay, as well as the common presence of Tibito Tephra at late Phase 5 ditches. 


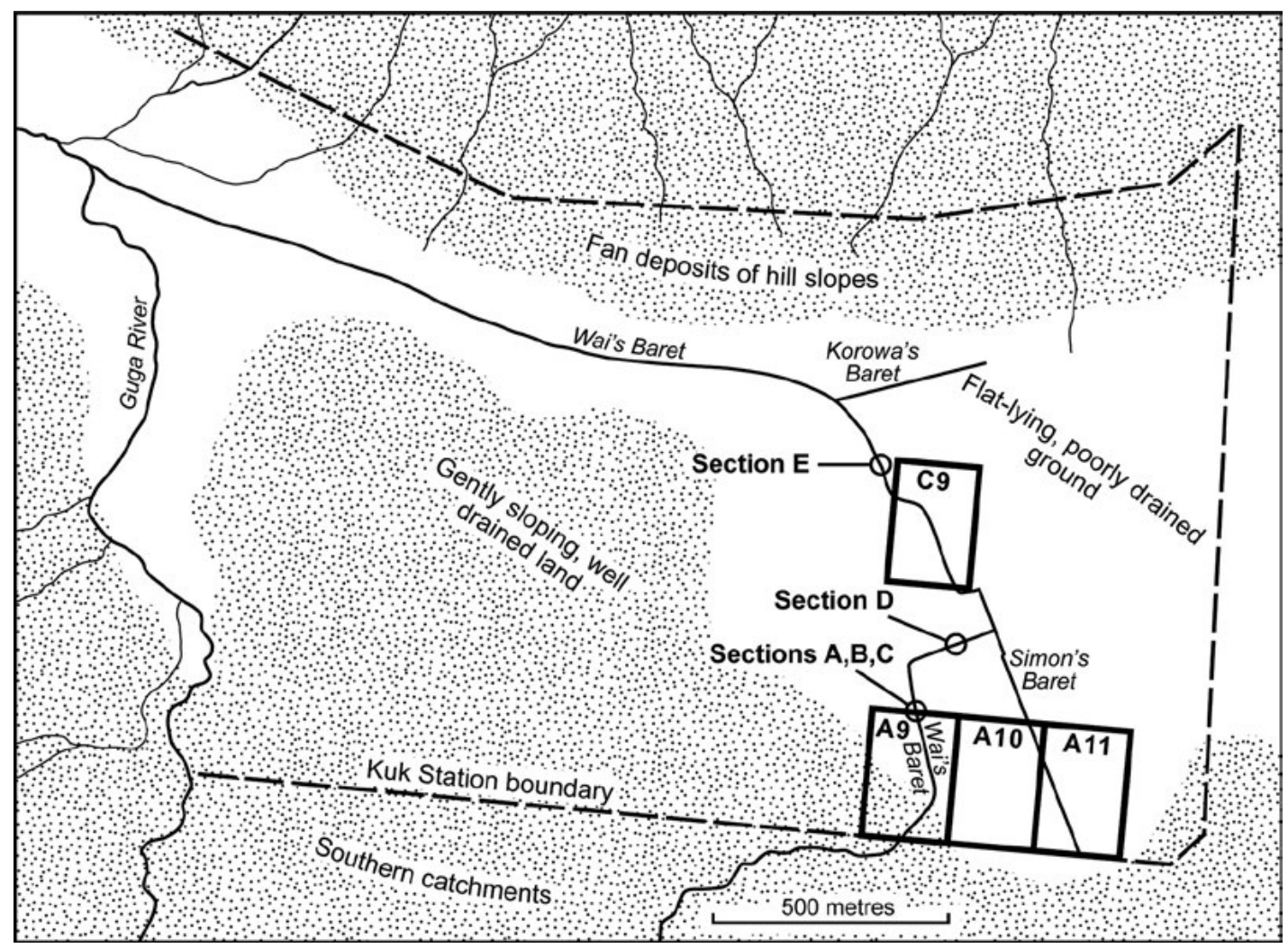

Figure 15.2 The framework of Phase 5 drainage at Kuk Swamp, showing the location of the profiles across the major disposal channel, Wai's Baret, which are displayed in Figure 15.7.

Block A9, blocks A10 and A11 and block C9 are three sample areas where detailed analysis of ditch morphology and networks was carried out.

Source: Drawing by Philip Stickler after Bayliss-Smith et al. (2005: Fig. 1), reproduced with permission.

\section{The major disposal channel: Wai's Baret}

As in previous phases, the problem facing those wishing to establish gardens in Kuk Swamp at the start of Phase 5 was finding a way to remove the stream waters that enter the swamp from its southern catchments, as well as to get rid of locally generated runoff. The annual water surplus (precipitation minus evapotranspiration) is about $1700 \mathrm{~mm}$ (McAlpine, Keig with Falls 1983: Fig. 8.11; cf. Hughes, Sullivan and Yok 1991: 229). All of this water needed to escape across the surface of Kuk Swamp, which has shallow gradients of between 1:130 and 1:430. The scale of the problem facing the former inhabitants of Kuk can be gauged from the situation in the 1930s, after perhaps a generation of total abandonment of drainage effort (see Chapter 16, section 'Dating Phase 6 at Kuk'). In April 1933, Kuk Swamp was covered in thick cane grass and largely under water. The first patrol of Mick Leahy and Jim Taylor struggled to cross the area, carrying their dogs over the deeper pools (Gorecki 1979b: 26; cf. Chapter 23, section 'The prelude').

The former channels of prehistoric drainage visible on the ground surface after the establishment of the Research Station in 1969 were at first mistaken for natural streams by the archaeologists beginning work there in 1972. The channel initially called Creek 2 (Golson 1976: Fig. 3; see Fig. 15.3 here) was later shown to be artificial by its straightness and right-angled changes of direction as it flowed across the A and B blocks, so it was called Wai's Baret, the first disposal channel to be named for one of the workmen (see Figs 15.2 and 15.4). 


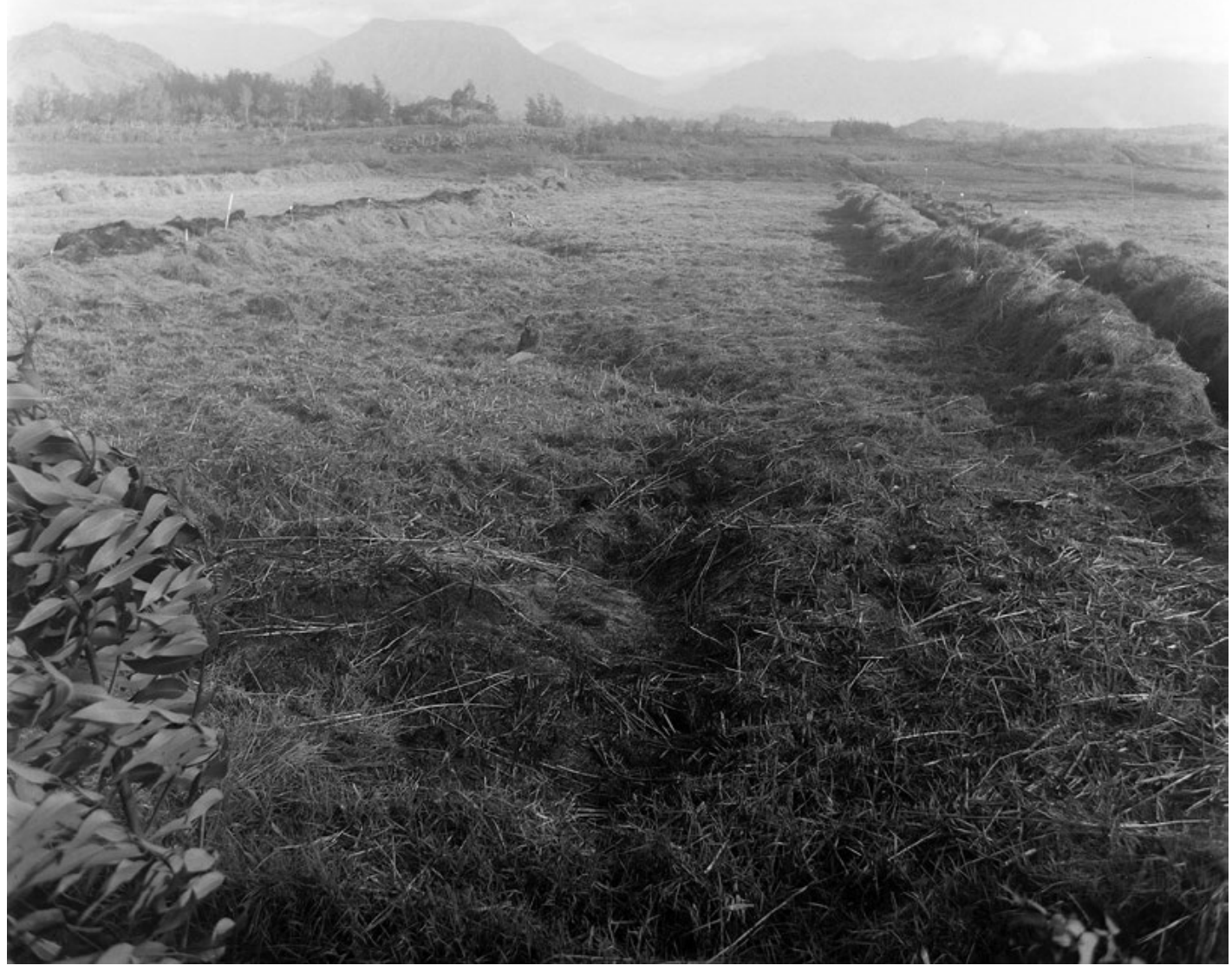

Figure 15.3 Looking SSE over the sinuous channel that developed along the course of Wai's Baret in block A9f after the abandonment of swamp drainage for cultivation at Kuk, perhaps around AD 1900. Source: Photograph by Wal Ambrose, Kuk archive, 1972.

A crucial factor in this interpretation was the short stretch of ditching at the intersection of E-W Rd 2 and N-S Rd 4, which links the northern end of the channel crossing the A and B blocks from the southeast with the southern end of that crossing the $\mathrm{C}$ and $\mathrm{D}$ blocks to the northwest (Fig. 15.4 Inset 2). Because this short stretch was present in the walls of drain B9g/h, but not in those of the next drain to the west, B9f/g, we can be certain that the right-angled bend that Wai's Baret makes at this point is an original and deliberate feature. As described in Chapter 14, section 'Major disposal channels', our later investigations implied that the northerly continuation of Wai's Baret from the middle of the B blocks was cut along the course of the previous Neringa’s Baret. 


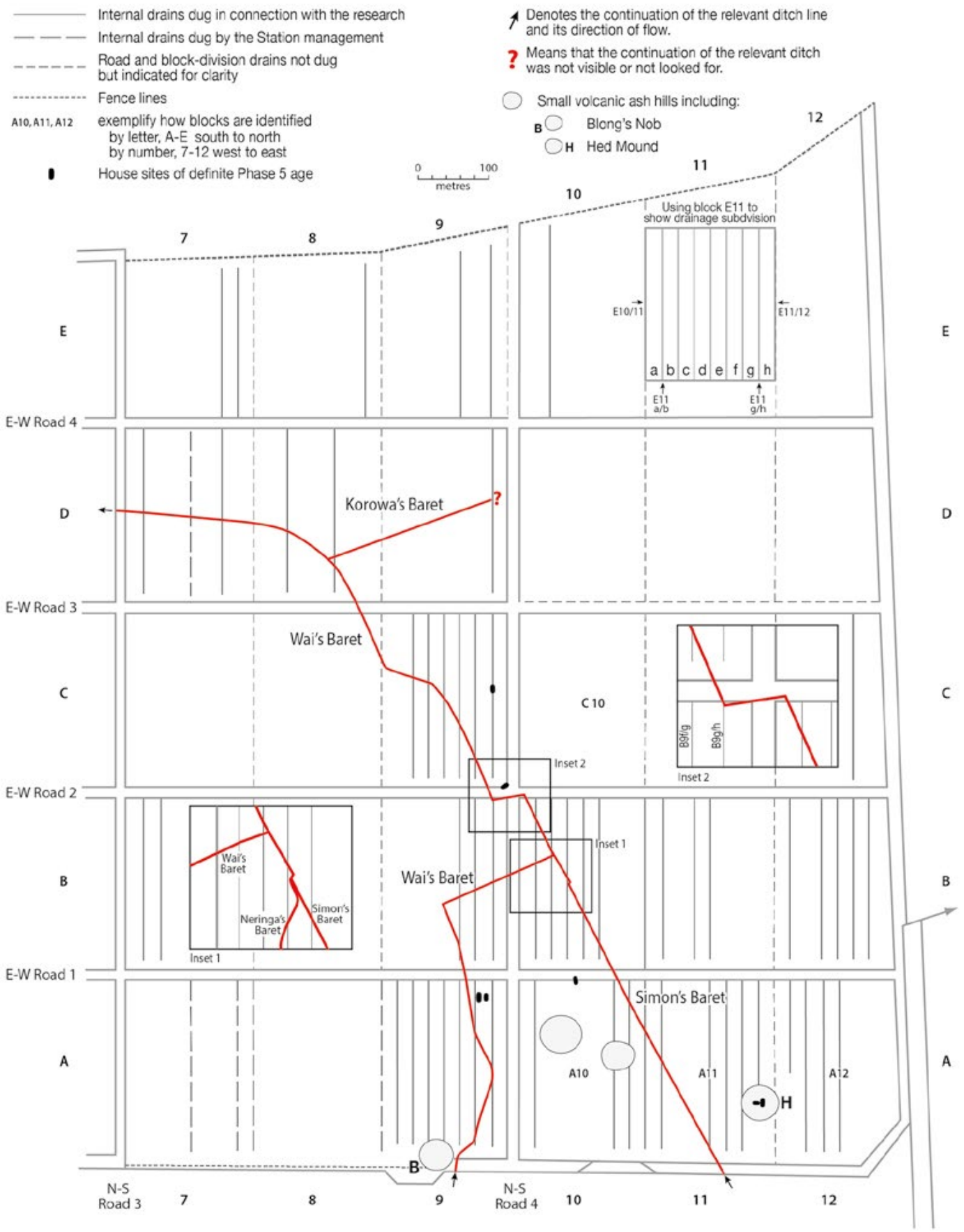

Figure 15.4 Baret draining the SE margins of Kuk Swamp and Korowa's Baret performing a similar role in the NE.

Inset 1 shows how, whether digging proceeded from the north or south, Simon's Baret reused some of the existing channel of Neringa's Baret, including the kink (see Fig. 14.4 Inset 2), which continued in existence into Phase 6 (see Fig. 16.3). Inset 2 shows the short stretch of ditching that was crucial in the development of the argument for the artificial nature of swamp drainage during Kuk Phases 4-6. On present evidence houses made their first appearance in the swamp at a late stage of Phase 5.

Source: Jennifer Sheehan, CartoGIS Services, College of Asia and the Pacific, ANU. 


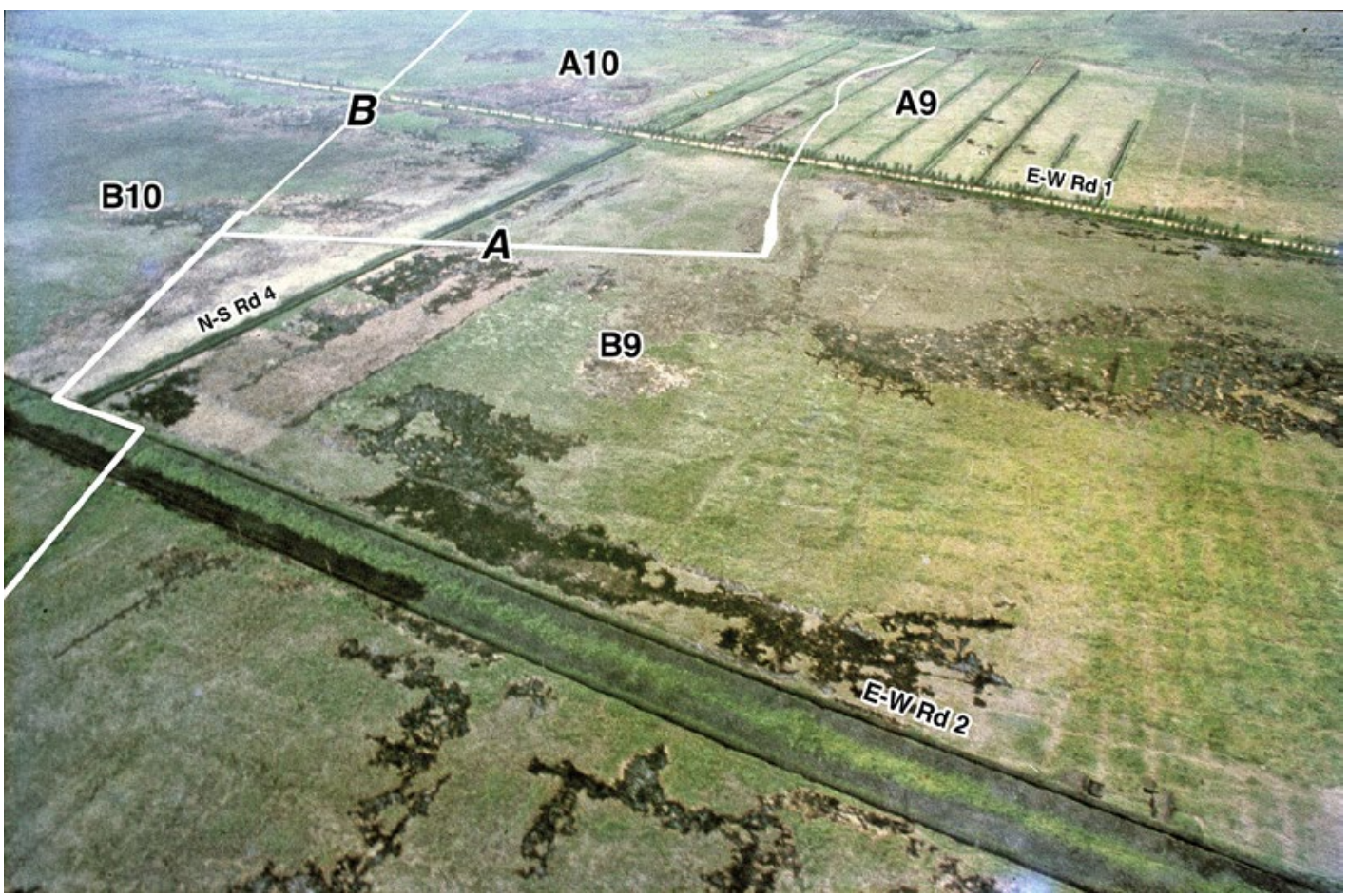

Figure 15.5 View SSE showing Wai's (A) and Simon's (B) Barets, the courses of which have been digitally enhanced.

Wai's Baret moves from the southern catchment through block A9, the one almost fully provided with its complement of modern drains, and crosses E-W Rd 1 into block B9, where it makes a right-angled bend from NNW to ENE. It crosses the future line of N-S Rd 4, whose western road drain has been dug, into block B10. Here it makes another right-angled bend, from ENE back to NNW. At this bend it is joined by Simon's Baret, which comes in on a direct SSE-NNW line from the southern catchment (see Fig. 15.6). From its junction with Simon's, Wai's Baret continues NNW to the line of E-W Rd 2, whose north and south road drains have been dug, and makes a right-angled bend WSW. The situation here is best understood by comparing it with Inset 2 of Figure 15.4.

Source: Photograph by Wal Ambrose, Kuk archive, 1972.

The distinctive nature of the channel's course here and elsewhere suggests that its purpose was to mark some kind of land boundary as well as to lead water from the southern catchment to the Guga River outfall. Together with Simon's Baret, one of its tributaries, Wai's Baret was the primary means whereby the southern part of Kuk Swamp was brought into agricultural use at the start of Phase 5 (see Figs 15.5 and 15.6).

The earliest channel in the Wai's Baret complex, which can be termed early Phase 5, was the deepest of four channels dug on the same line (Fig. 15.7; see Fig. 15.2 for location of profiles). It had a cross-sectional area of about $3.0 \mathrm{~m}^{2}$, which means it was appreciably larger than its Phase 4 equivalent, Neringa's Baret (about $2.0 \mathrm{~m}^{2}$, see Chapter 14, section 'Major disposal channels'). The mid-Phase 5 channel in Wai's Baret is poorly represented, but it appears to have had a cross-sectional area of about $2.5 \mathrm{~m}^{2}$. The late Phase 5 channel was wider and shallower than those of the two previous subphases and its basal fill commonly contained lenses of Tibito Tephra. The cross-sectional area of the late Phase 5 channel was about $2.0 \mathrm{~m}^{2}$, which implies approximately a 33 per cent decline in hydraulic capacity since the beginning of Phase 5 . The last and smallest channel postdates Tibito Tephra and can therefore confidently be assigned to Phase 6. 


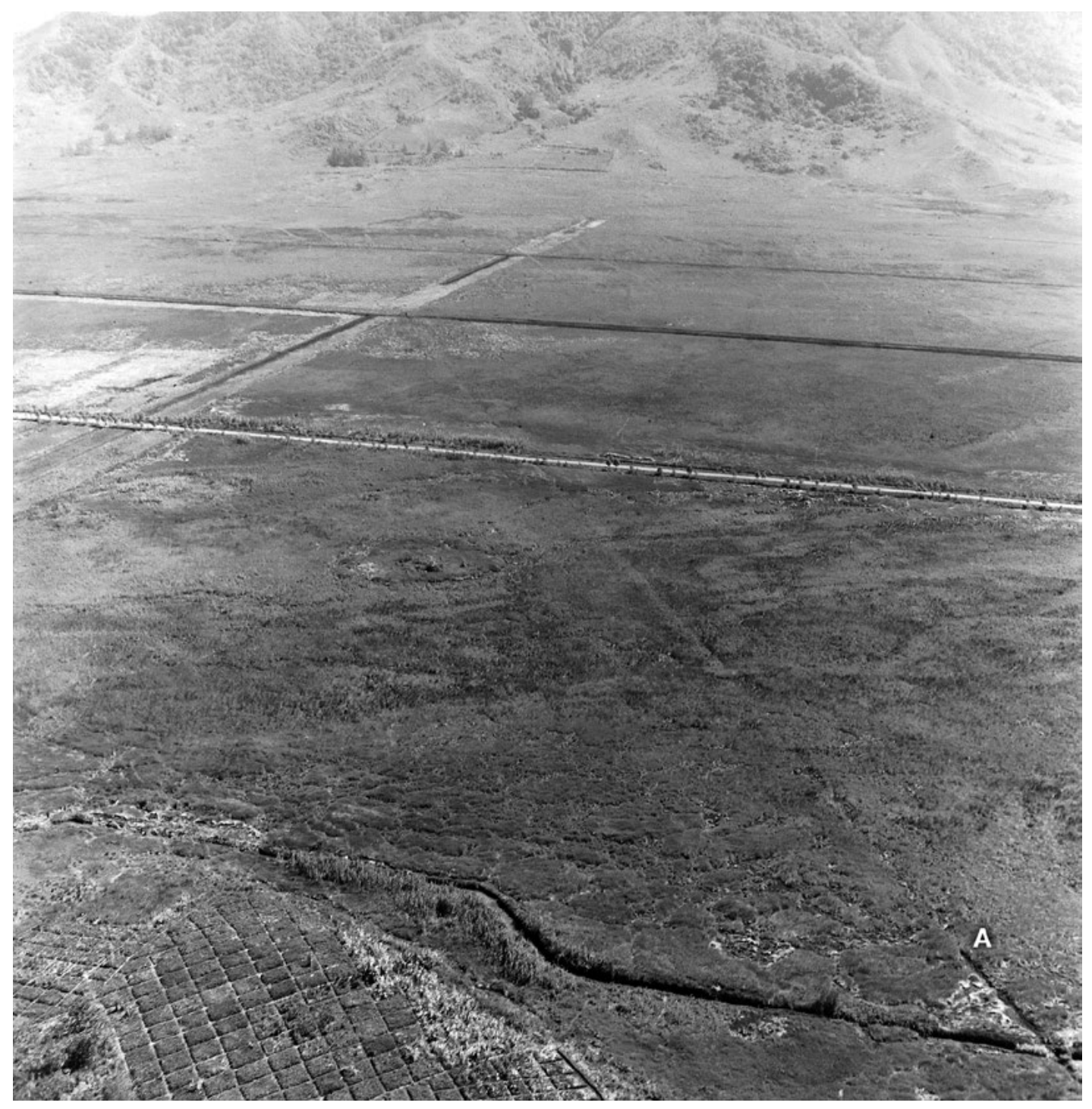

Figure 15.6 View slightly west of north from the Kuk southern boundary drain showing the course of Simon's Baret (A) NNW from here and across E-W Rd 1 towards the junction of the drains of the future E-W Rd 2 and N-S Rd 4.

In the background are the slopes of Ep Ridge and in the foreground the grid of sweet potato gardens on rising ground above the swamp.

Source: Photograph by Wal Ambrose, Kuk archive, 1972.

Increased land clearance, burning and soil tillage in the Kuk Swamp catchment, as well as increasingly intense activity within the swamp itself, must all have contributed to a higher sediment load in the disposal channels. As a result, we might expect the clogging of drainage and a need for more frequent cleaning out of channels. Yet the data for Wai's Baret suggest a progressive decline, from early Phase 5 to late Phase 5 and into Phase 6 times, in the amount of labour invested in the maintenance of the major disposal channel. As the discharge carried by Wai's Baret cannot have declined at all between early Phase 5 and Phase 6 , the inference must be that Wai's Baret became less and less efficient and was progressively more prone to overbank flow during high discharge events. 


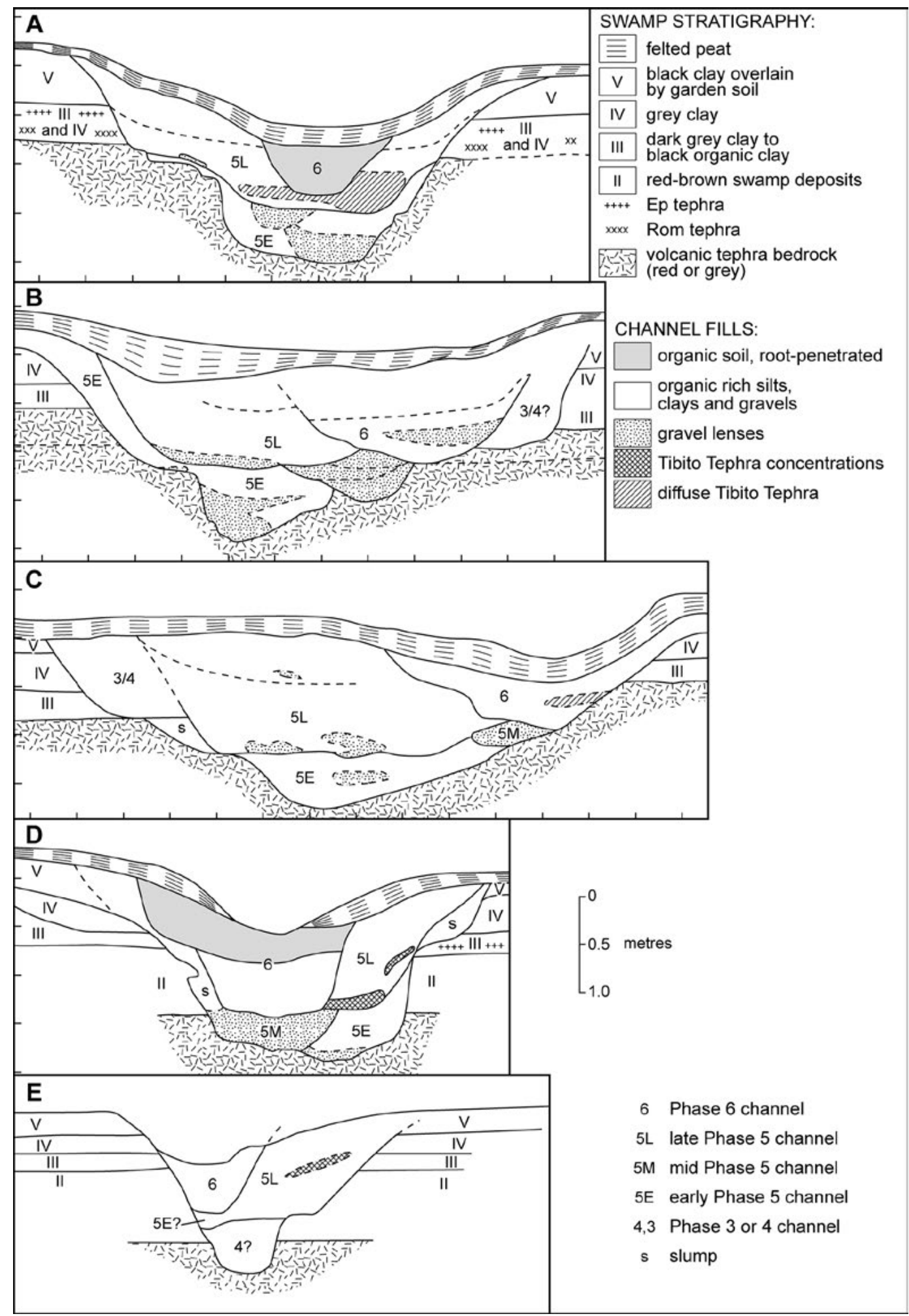

Figure 15.7 Five cross-sections through Wai's Baret.

The profiles cover the history of the channel from early Phase 5 through mid and late Phase 5 into Phase 6 . Section A is at the north wall of the south drain of E-W Rd 1 and $B$ and $C$ at the south and north wall of the north drain, respectively. Note that $C$ is a mirror image of the actual section. Section $D$ is at the east wall of drain B10W and $E$ at the south wall of the south drain of E-W Rd 3.

Source: Drawing by lan Agnew after Bayliss-Smith et al. (2005: Fig. 2), reproduced with permission. 
We can compare Wai's Baret in Phase 5 with the main modern drain along Kuk's southern boundary, first dug in 1969. At the point where runoff from the southern catchment enters Kuk Swamp (see Figs 15.2 and 15.4), its cross-sectional area is $3.9 \mathrm{~m}^{2}$. Measurements of discharge at this point carried out by Philip Hughes and Marjorie Sullivan over a 20-month period in 1986 and 1987, combined with their longer-term observations in the mid to late 1970s, indicated that overbank flooding occurs on average a little more than once a year. The population and landuse intensity in the catchment today is higher than in prehistoric times and it is likely that flood peaks are larger today than in the past because there is more bare ground, especially in gardens and coffee plantations (Hughes, Sullivan and Yok 1991: 234-235). Hence the major disposal drain dug for the modern Station needed to be larger than its prehistoric equivalents to cope with all but the largest flood events.

We can conclude that the early Phase 5 cross-section of Wai's Baret, which was about $3.0 \mathrm{~m}^{2}$ in area, was probably effective in preventing flooding of garden lands adjacent to the channel except for the 'once in a year' large flood. Unless we invoke a drier climate, we must conclude that successive phases of Wai's Baret would have been progressively less efficient at preventing flooding. Possible reasons for this disintensification are discussed below.

\section{Tributary channels}

\section{Simon's Baret}

Occupying an intermediate place in the drainage hierarchy between the major disposal channel and the minor field ditches were tributary channels such as Simon's Baret, which serviced the field drains principally in blocks A10, A11 and B10. A section through this channel (Fig. 15.8) shows the same progressive decline in drainage capacity that characterises Wai's Baret. The deepest and narrowest channel is the earlier of the two that date from Phase 5. If the cross-sectional area is calculated below the level of the upcast grey and black clay (a proxy measure for the Phase 5 land surface), then its channel capacity is about $1.8 \mathrm{~m}^{2}$, some 60 per cent of the size of Wai's Baret, into which it flowed. The upcast clay on the ditch's northern bank would be consistent with the digging efforts of a man working his way upstream with his paddle spade and throwing the spoil upwards to his left (assuming he was right-handed).

The later Phase 5 channel is $250 \mathrm{~mm}$ shallower than its predecessor, but is slightly wider, so that its capacity was only slightly less, about $1.7 \mathrm{~m}^{2}$. Tibito Tephra is present in the fill about 200 $\mathrm{mm}$ above the base, suggesting that by the mid-AD 1660s the channel's cross-sectional area had fallen to about $1.5 \mathrm{~m}^{2}$. The change since the onset of Phase 5 amounts to a 14 per cent decline in channel capacity, a less drastic change than the 33 per cent decline in the capacity of Wai's Baret. 


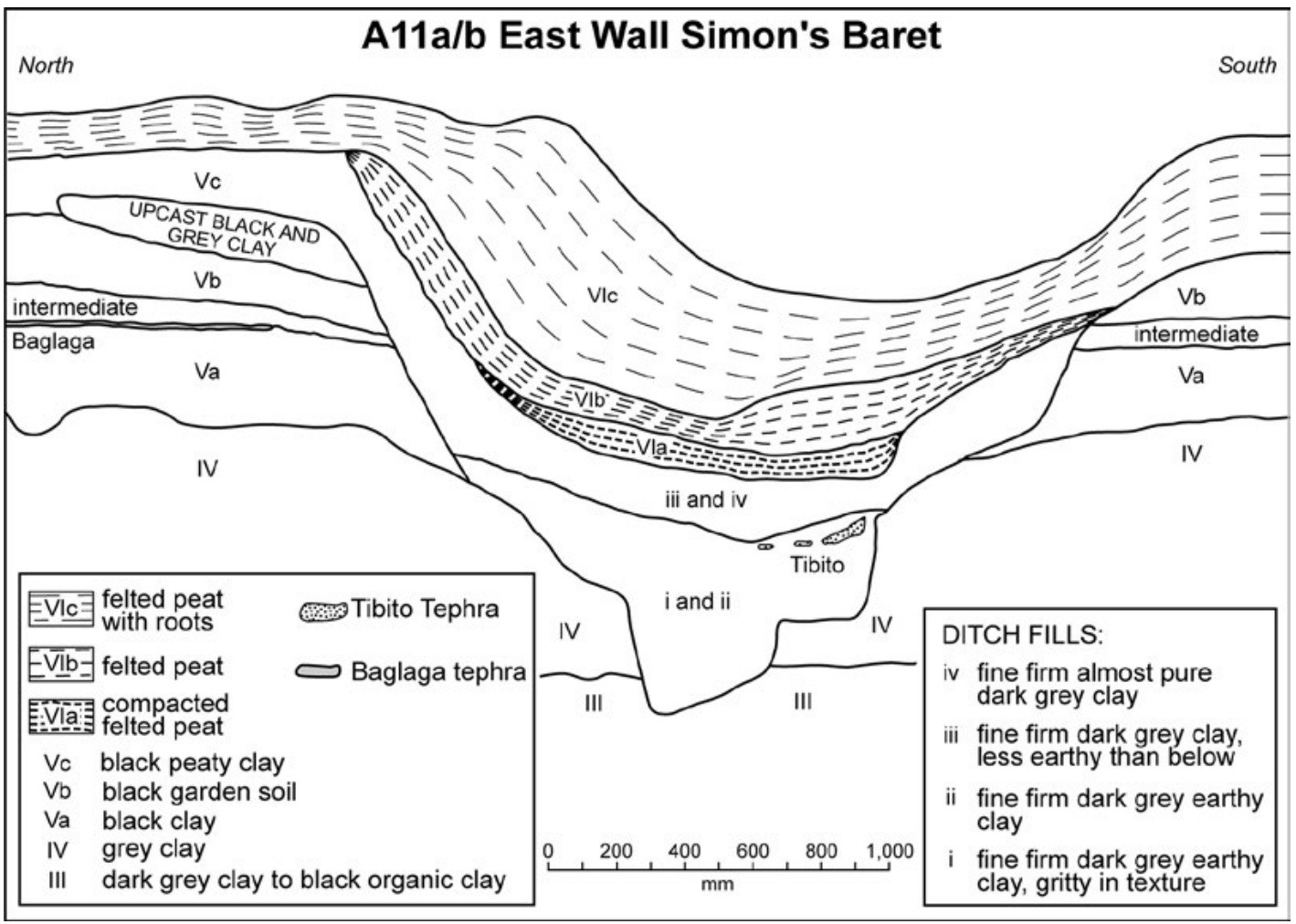

Figure 15.8 Cross-section through the tributary channel, Simon's Baret, in the east wall of drain A11a/b. The profile shows evidence of two subphases of use in Phase 5, followed by the fall of Tibito Tephra after which the Phase 6 channel was dug considerably shallower and wider.

Source: Drawing by Philip Stickler based on a field recording, Kuk archive, 1973.

\section{Korowa's Baret}

Further evidence for minor disposal channels is available from the northern part of Kuk Swamp, in block D9 (see Figs 15.2 and 15.4), paralleling the Phase 4 channel called Feature 7 (Figs 14.2, 14.4 and 14.7) and interpreted as a minor disposal channel serving the drainage of the northeast margin of the site. In Phase 5 there is a second tributary of Wai's Baret, known as Korowa's Baret, which shows evidence of four subphases of use in Phase 5, the last of which is marked by traces of Tibito Tephra (Fig. 16.6). All of these subphases show the same tendency to shallow and widen during Phase 5, as evident in Wai's and Simon's Barets. The deepest ditch is interpreted as an early Phase 5 channel. When it came to be cleaned out, the next channel to be dug was $100 \mathrm{~mm}$ shallower and about $500 \mathrm{~mm}$ wider than its predecessor, and this trend was repeated in the next, mid-Phase 5 channel. These three early to mid-Phase 5 channels all have similar cross-sectional areas below the level of grey clay, estimated to be about $1.7 \mathrm{~m}^{2}$.

The late Phase 5 channel, which has traces of Tibito Tephra in the top of its fill, was dug to be even wider, but its flat base is also about $200 \mathrm{~mm}$ shallower, so it has a smaller cross-sectional area (about $1.5 \mathrm{~m}^{2}$ ). If we take the average of the estimated cross-sectional areas of the early and mid-Phase 5 channels $\left(1.74 \mathrm{~m}^{2}\right)$, then the change from early/mid to late Phase 5 represents a 14 per cent decline in channel capacity, exactly the same proportional decline as we have estimated for Simon's Baret. 


\section{Minor field ditches}

The field ditches of Phase 5, in contrast to the narrow slot-type ditches of the preceding phase, are generally trapezoidal in shape, flat-bottomed and steep-sided (Fig. 15.9a, 15.9c and Fig. 15.10). When measured from field data using the methods already described (see Chapter 14, section 'Field ditches: Shape and size'), most of these ditches have a depth of 300-600 mm below the top of black clay (mean depth $430 \mathrm{~mm}$ ). In terms of width, typically they are 600-800 mm wide at this same level (mean width $679 \mathrm{~mm}$ ). Figures 15.11 and 15.12 summarise some statistics relating to the depths and widths of Phase 5 field ditches compared to their equivalents in previous phases. The Phase 5 sample includes field ditches both from block C9 in the lower-lying part of Kuk Swamp and from A9 at the swamp margins, 250-500 m further to the south, but we have analysed them as an aggregate sample because there is little or no difference in ditch morphology between the two areas.
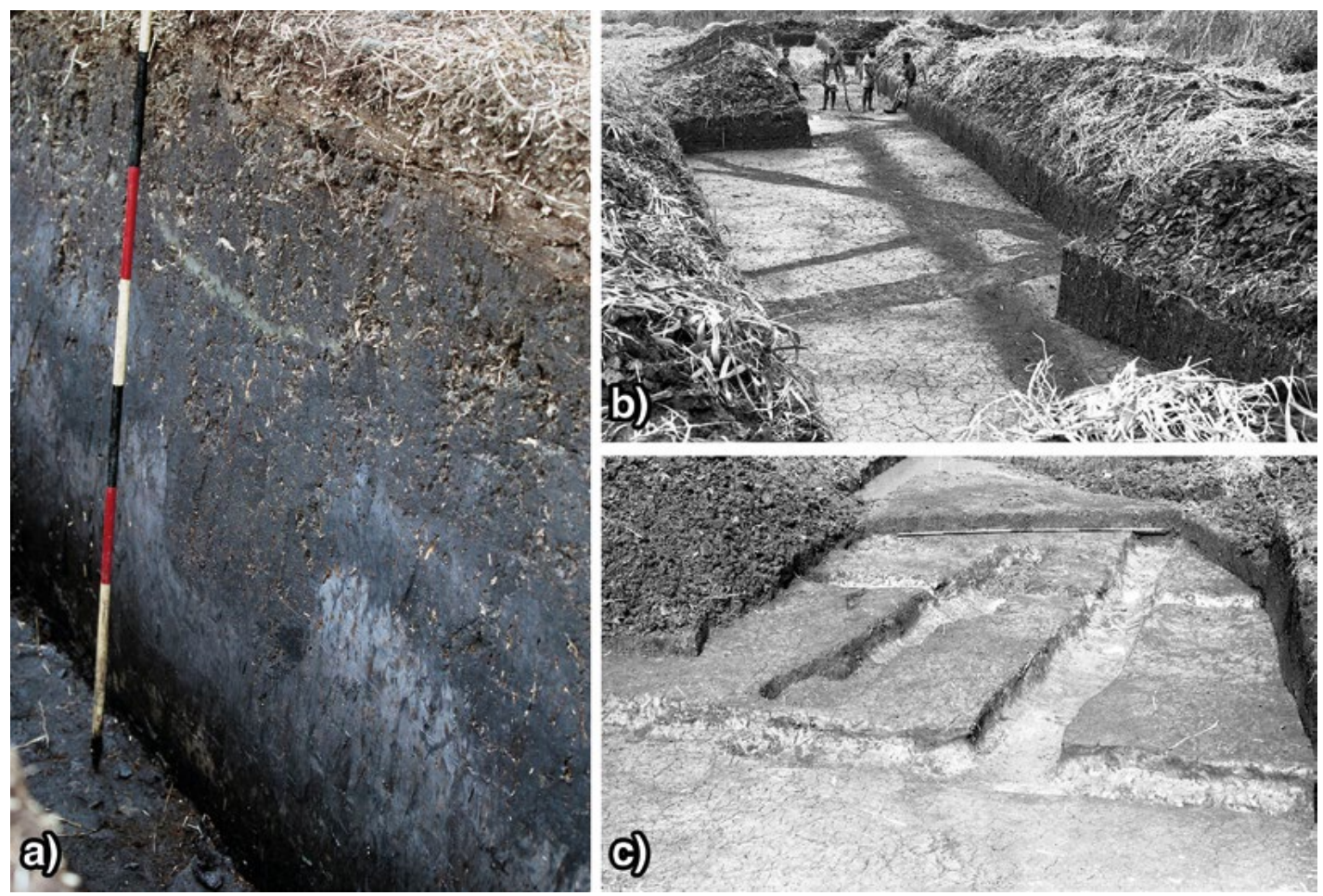

Figure 15.9 Three views showing the shape and size of Phase 5 ditches.

a) A view of the west wall of drain A10g/h, a $1 \mathrm{~m}$ wide and $1.5 \mathrm{~m}$ deep structure that cuts fairly acutely across a flat-bottomed, steep-sided ditch dug from above black clay through new grey clay and black clay into the main grey clay layer. The ditch was well filled when a barely dipping layer of Tibito Tephra was deposited across it, showing it to be an early Phase 5 feature. b) is a companion picture to Figure 13.10, where the focus is on a major arterial ditch of Phase 3, Denham's feature 393. Note the younger ditches that cut across it. The nearest and widest of these is definitely Phase 5 because there is Tibito Tephra clearly exposed in and limited to its fill. The narrower ditches are likely to belong to different stages of the same phase. c) A view west over the right-angled junction of two Phase 5 ditches excavated at the northern end of block A12d. The ditches of Figure $15.9 \mathrm{~b}$ and $15.9 \mathrm{c}$ are shown at the level of grey clay, as are other features, like the Phase 3 'trough' that runs parallel to the tributary ditch. The ranging pole is graduated at $200 \mathrm{~mm}$ intervals.

Source: Photographs by Klim Gollan, Kuk archive, 1975.

A profile drawing of the south wall of the excavation accompanying a prior publication of this plan (Denham, Golson and Hughes 2004: Fig. 12) shows the full depth of the north-south ditch (390) to have been at least $400 \mathrm{~mm}$, half of this above the level of grey clay. Figure 15.9c shows the ditches and other features at the top of grey clay, which was the level from which they were excavated. 
Because their widths are quite variable (see Fig. 15.12), the cross-sectional areas of Phase 5 ditches also vary, but usually within the range $0.1-0.4 \mathrm{~m}^{2}$. For a sample of 16 field ditches in block A9, the cross-sectional area of the channel below the level of black clay averaged $0.295 \mathrm{~m}^{2}$, which represents three times more volume excavated per ditch than in Phase 4, but achieving a similar depth of land drainage. In both phases, the modal depth of field ditches below black clay was $300-400 \mathrm{~mm}$, but their shapes are radically different. It would appear that the Phase 5 cultivators were actively seeking to generate more soil in the context of a regime of soil tillage that was in operation (see below, 'Phases 3, 4 and 5 compared').

All Phase 5 ditches give the appearance of having been dug and smoothed with wooden spades rather than the digging sticks that are inferred for Phase 4. The main difference is in shape, as represented by basal width, maximum width and cross-sectional area, rather than depth. The evidence does not allow us to measure changes in capacity between early and late Phase 5 ditches, but in many cases shallowing can be detected.
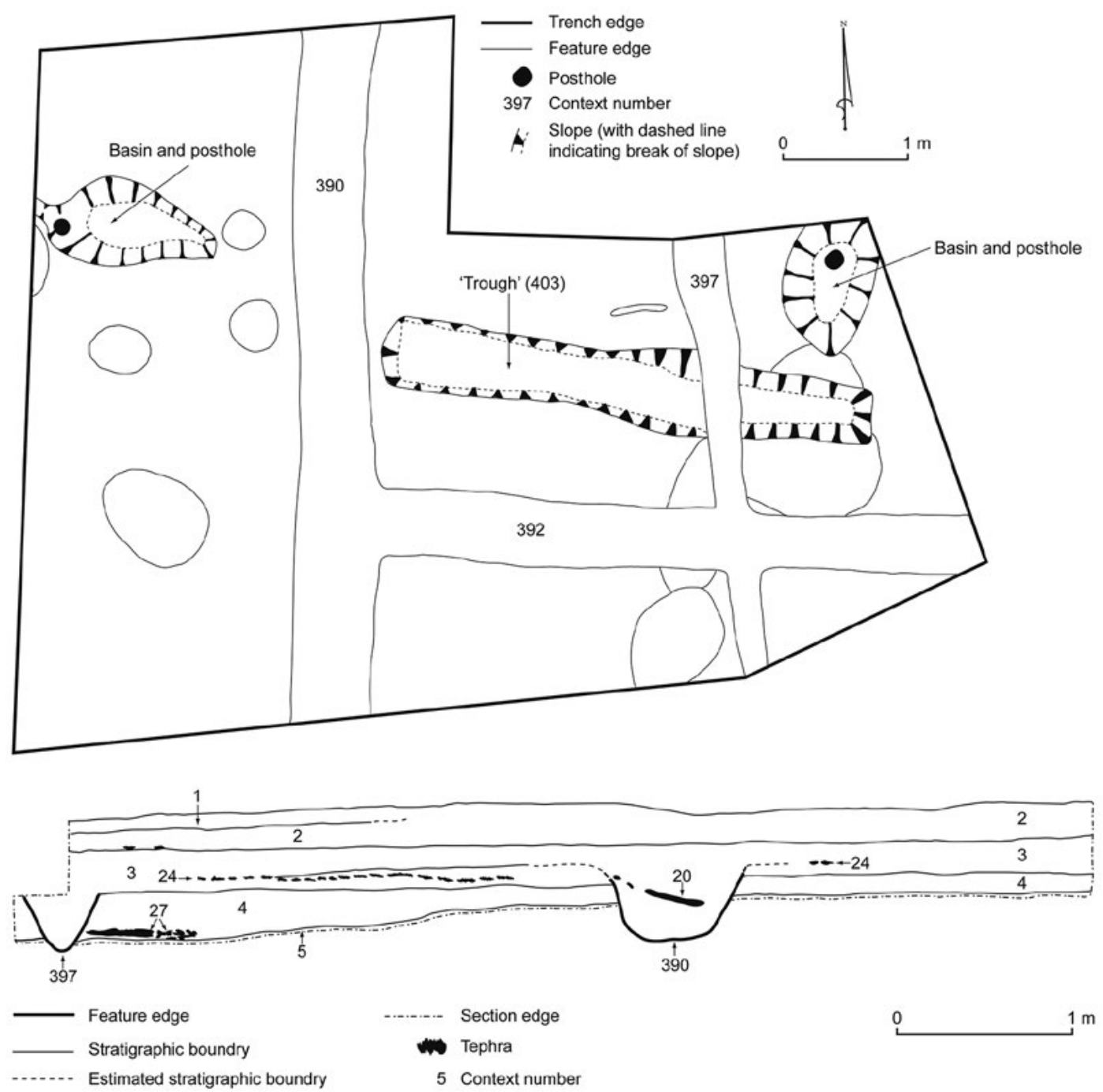

Figure $15.10 \mathrm{~A}$ plan of the excavation in Figure $15.9 \mathrm{c}$, showing the right-angled junction of two Phase 5 field ditches, 392 with 390. Other features include an unusual 'trough' (403) of Phase 3 age and, in the NW corner of the excavation, a Phase 2 basin with posthole (see Fig. 12.10).

Source: Drawing by Tim Denham from a field plan by Jack Golson of 1975, Kuk archive. 

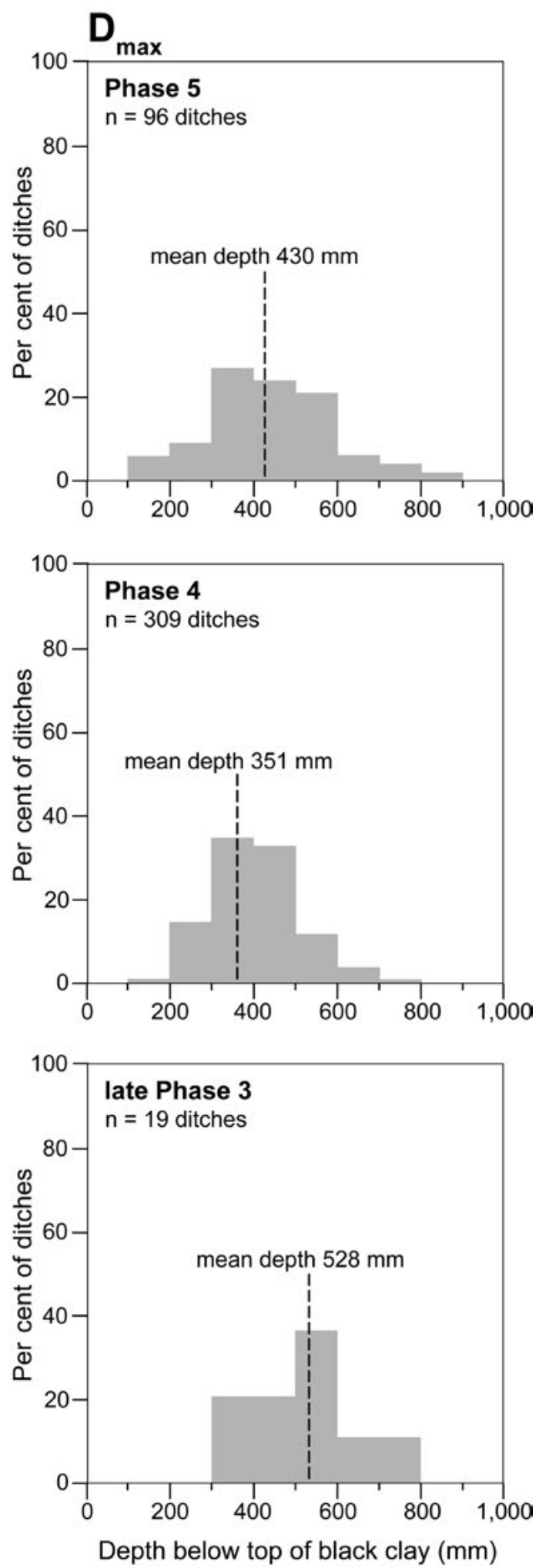

Figure 15.11 The depths of a sample of field ditches from late Phase 5 compared to those from the two previous phases, Phase 4 and Phase 3.

In each case, depths are measured from the top of black clay (Dmax). Field ditches in Phase 5 have the same modal depth as those in Phase 4 (300-400 mm), whereas many Phase 3 ditches are somewhat deeper, although the sample size for Phase 3 is too small for statistical significance. These aggregate statistics were derived from measurements taken in the field from ditches recorded in the north-south Station drains and positively identified according to phase in either the west wall, the east wall or both. For late Phase 3, there were 34 identified field ditches in blocks A11, A12 and B11 where measurements were available; for Phase 4 , there were 240 different field ditches available in A9, A10, A11, C9, D7, D8 and D9; and for Phase 5, 126 different ditches were available in A9, A10, A11 and C9. In many cases the availability of measurements from both east and west wall partners enabled us to enlarge the sample, but on the other hand, the flooding of some drains obscured the base of ditches and so prevented any Dmax measurement from being made.

Source: Drawing by Philip Stickler based on measurements and calculations by Tim Bayliss-Smith on field data from the Kuk archive, 1972-76. 

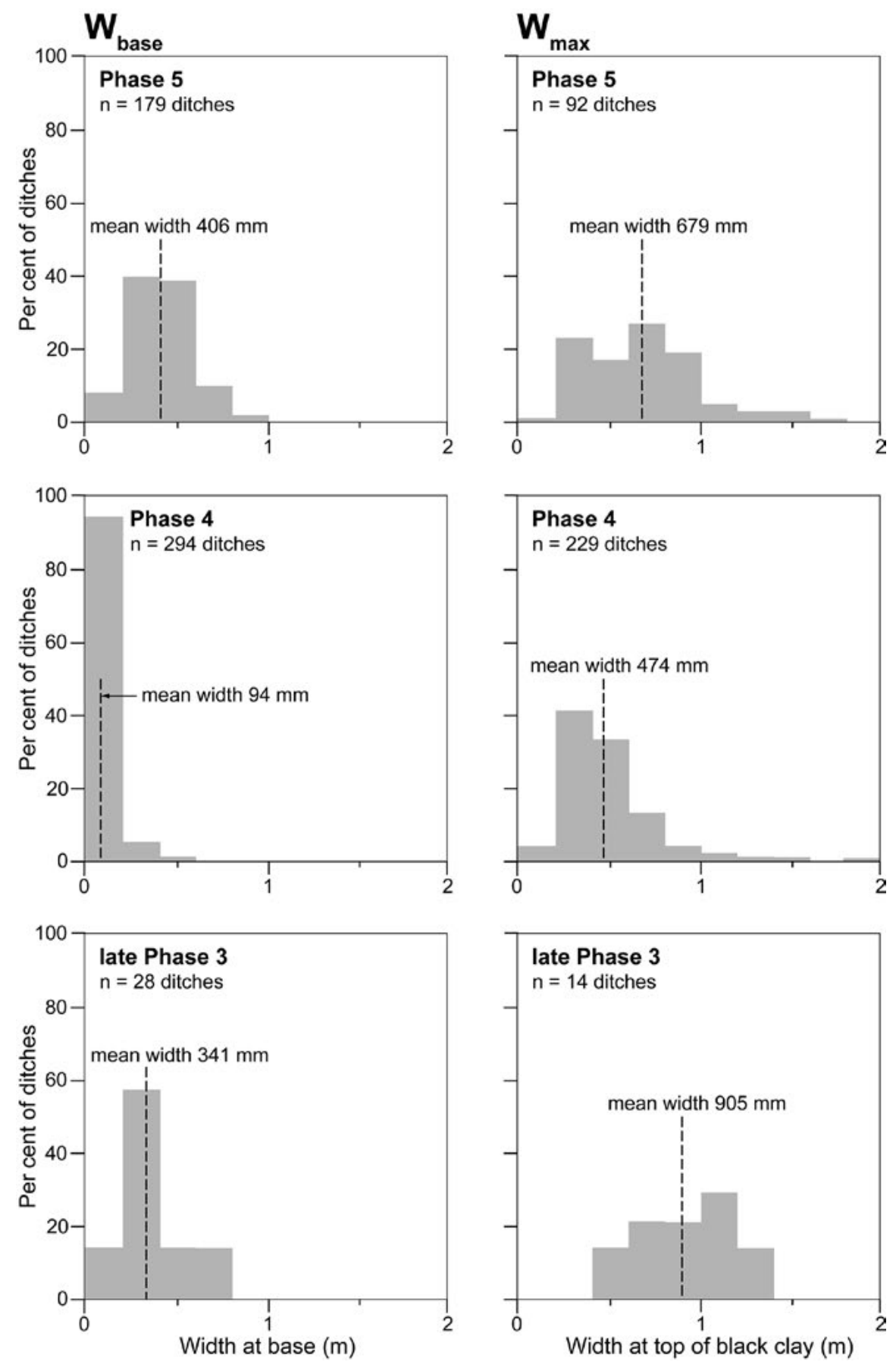

Figure 15.12 The widths of a sample of field ditches from late Phase 5 compared to examples from Phase 4 and Phase 3.

To obtain these width statistics we used the same sample that was measured for depths, but with widths adjusted to remove the distortion that results from cross-sections that are not at right angles to the course of a ditch. When ditch sections were redrawn perpendicular to the direction of flow, true lateral measurements could be made. Because some features of some ditches in the Phase 5 sample had been obliterated by later ditch digging, not all width measurements could be recorded for every field ditch, so that sample sizes vary somewhat between the different types of measurement. The maximum width measure is taken from where the ditch profile starts to level out at the top of black clay (Wmax). Basal width is measured $10 \mathrm{~mm}$ above the lowest point of the ditch (Wbase). Both measures show that the Phase 5 field ditches resemble those of Phase 3, whereas Phase 4 ditches have a radically different shape, being considerably narrower especially towards their base. Source: Drawing by Philip Stickler based on measurements and calculations by Tim Bayliss-Smith on field data from the Kuk archive, 1972-76. 


\section{Ditch networks and field systems}
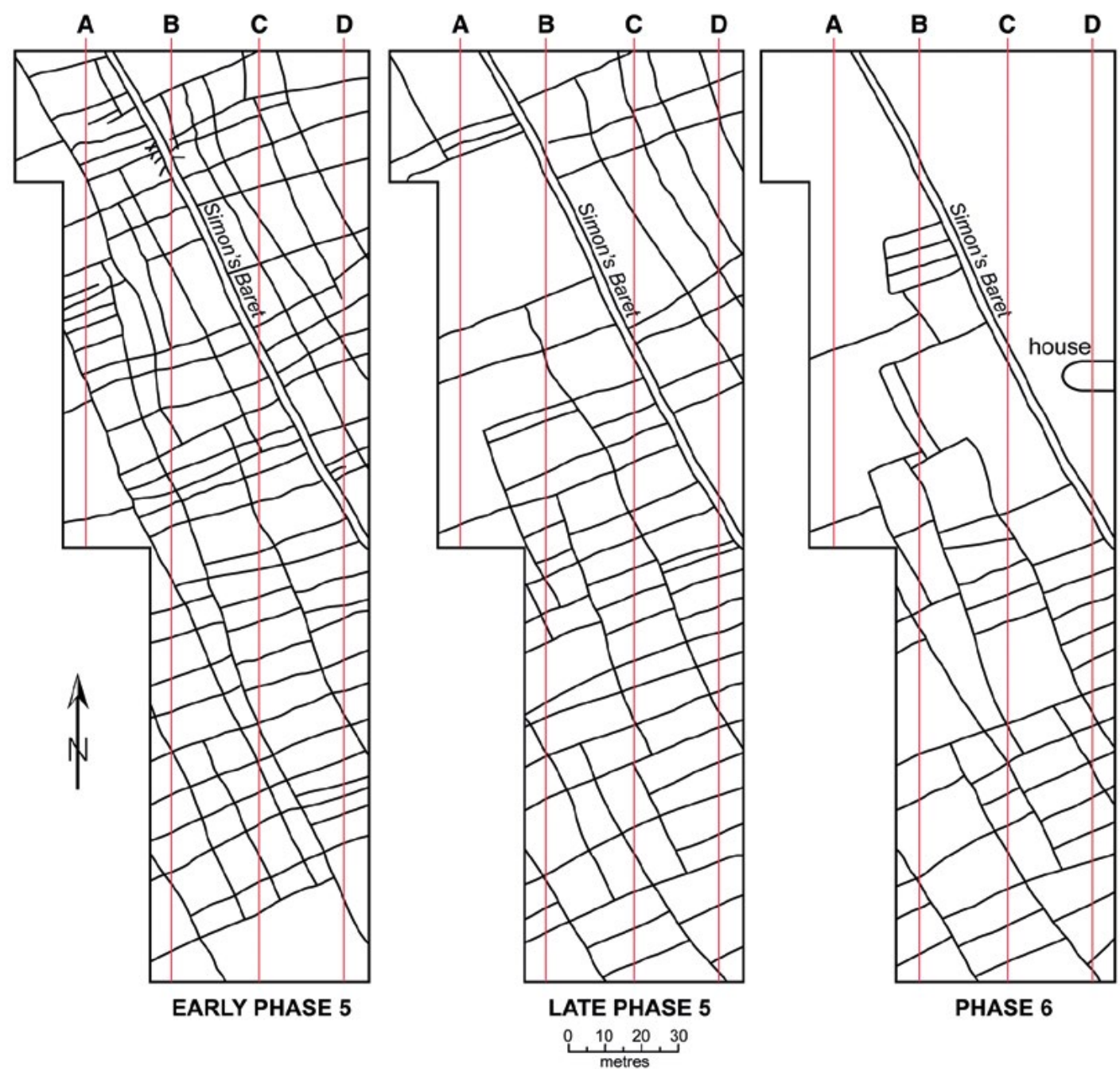

Figure 15.13 Ditch networks of early and late Phase 5 and Phase 6 in blocks A10 and A11.

The reconstructions are based on the intersection of ditches with Station drains $A 10 f / g(A), A 10 \mathrm{~g} / \mathrm{h}$ (B), A10/11 (C) and A11a/b (D), as well as limited excavation (cf. Fig. 14.12 and Fig. 16.12 for similar exercises for Phase 4 and Phase 6 respectively). Note the house site east of Simon's Baret in the Phase 6 panel.

Source: Drawing by lan Agnew after Bayliss-Smith et al. (2005: Fig. 4), reproduced with permission.

Our most complete reconstruction of drainage networks for early Phase 5, late Phase 5 and Phase 6 is from blocks A10 and A1 1 (Fig. 15.13), based in each case on a graphical extrapolation of the ditches exposed in Station drains plus some evidence from open-area excavation. Although such maps cannot be wholly accurate, they should not contain systematic bias and so are valid sources for measurements of field size and drainage density. The area itself, in blocks A10 and A11, can be regarded as intermediate between the two extremes of seasonally dry swamp margins, like block A9, and deep low-lying swamps where drainage was always problematic, like block C9.

A comparison of early Phase 5 and late Phase 5 in the chosen blocks shows clear evidence for some reduction in drainage activity over this period, even though we might expect that surviving field evidence for early Phase 5 would be the more fragmentary. In fact, early Phase 5 ditches are the more numerous, forming a widespread network. The late Phase 5 ditches, including some with Tibito Tephra, form a less extensive network of slightly shallower ditches, but until 
the middle AD 1600s some activity continued in all parts of A10 and A11. It is in post-Tibito times (Phase 6) that drainage activity northeast of Simon's Baret virtually ceased, as described in Chapter 16.

The reduction in ditch-digging activity in this part of Kuk Swamp during Phase 5 is confirmed by the drainage density measure, which is the number of metres of ditch dug per hectare of wetland cultivated. For the area southwest of Simon's Baret in blocks A10 and A11 (see Fig. 15.13), there were on average, in early Phase 5, $1740 \mathrm{~m}$ of ditch per hectare cultivated. This is a density not much less than had been generated some hundreds of years previously in Phase 4 times. By late Phase 5, drainage density had declined to $1240 \mathrm{~m} / \mathrm{ha}$ and there was to be a further small decline to $1090 \mathrm{~m} / \mathrm{ha}$ in Phase 6 .

The average dimensions of the 'fields' defined by the minor ditches also show the same trend of disintensification. Whereas early in Phase 5 the fields had average dimensions of $14 \times 7 \mathrm{~m}$, by the end of the phase fields were larger and more elongated, averaging $20 \times 9 \mathrm{~m}$.

\section{Artefacts, houses and pigs}

Compared with the evidence of ditches, other forms of archaeological evidence from Phase 5 are much more scattered and incomplete. However, as noted above, the ditches themselves suggest a change in emphasis from digging stick to paddle-shaped wooden spade as the primary tool of construction. The earliest dated wooden artefact from Kuk is one such spade, already mentioned as being found in a Phase 5 ditch and dated by associated wood to within the period between AD 1430 and 1650, which in the Kuk chronology is the second half of Phase 5 (cf. Chapter 19, section 'Long-handled implements'). It is in later Phase 5 also that definite houses appear for the first time at Kuk Swamp (Fig. 15.4), some situated on a low hill (Hed Mound) straddling the boundary between blocks A11 and A12, others on the margin of the swamp itself, all of them with a flanking runnel or ditch for drainage.

The firmest evidence for housing at Hed Mound begins with Harris's Periods V, VI and VII of activity there (Harris 1977: 7-9, Fig. 7; see Chapter 17, section 'Harris' excavations on Hed Mound 1977', Fig. 17.17C, D and E). The three periods are represented by three houses, labelled Houses 1, 2 and 3, replacing each other on the same spot on top of the hill. On the ethnographic evidence of a short lifespan for such houses and on the assumption that they were quickly replaced, Harris allows a duration of 30 years for his Periods V-VII. A fourth house and a perimeter fence belong here also, but cannot be precisely placed within the three periods (Harris 1977, Fig. 7, panel 7; Chapter 17 here, Fig. 17.17E). However, Harris argues (1977: 9) that the perimeter fence must have been at least partly in existence at the fall of Tibito Tephra, because some tephra was trapped at the base of posts. For him, therefore, the 30 years of Periods V-VII fall at the very end of Kuk Phase 5.

Where present, the lie of Tibito Tephra near the base of the handful of Phase 5 houses located within the swamp itself, where the house ditches are deeper, also points to a late Phase 5 date (see Fig. 15.4; cf. Fig. 17.3). This is the case for a house cut across by the south drain of E-W Rd 1 and for another at the very southeast corner of block C9, its ditch exposed in the walls of two converging road drains. Also, for a possible house on drain $\mathrm{C} 9 \mathrm{~g} / \mathrm{h}$, as well as for Lampert's Houses P and Q beneath the Phase 6 houses at the north end of block A9g (see Fig. 17.3), where the line of the house ditch could only be tracked at the surface of the grey clay. It is likely that there are more late Phase 5 houses at Kuk than the few discovered, either hidden below Phase 6 houses or elsewhere in the blocks between Station drains or with their house ditches unrecognised in drain walls. It may also be the case that there are others on top of the two uninvestigated hillocks in block A10, though the one cut through by drain A10f/g did not appear to show evidence of such use (Fig. 15.4). 
Harris (1977: 7) also conceded that the features he assigned, 'somewhat arbitrarily', to Period IV at Hed Mound could be evidence of habitation earlier in Phase 5 than the complex we have been discussing, though he thought them more likely to be related to agricultural activities (1977: Fig. 7, panel 4; Chapter 17 here, Fig. 17.17B). The features in question, which he called 'gullies', are generally very shallow and of varying widths. They were found over most of the excavated area, but their full extent could not be recovered because they were only visible where they cut into the grey clay subsoil of the hill. Even so, the remnants show cases of the combination of straight and curving courses that is characteristic of the house ditches of Periods V-VII. Indeed, what might be proposed as the most fully preserved example, represented by features 37-39 of Figure 1 of Harris 1977 (see Fig. 17.18 here), looks very like the houses of succeeding periods, as shown in Figure 7.5-7.7 of Harris 1977 (cf. Fig. 17.17C, D, E here). In Figure 7 of Harris 1977, features 37-39 are part of his Period IV and postdate feature 8, a presumed garden ditch that belongs to his Period III. This ditch has Tibito Tephra high in its fill and so is early Phase 5 in the Kuk sequence. In Figure 1 of Harris 1977 (Fig. 17.18 here), however, feature 8 is shown as cutting across feature 37 and thus as later than it. In discussion of this matter here, in the Hed Mound excavation section of Chapter 17, Harris affirms his confidence in the field drawing that is Figure 1 of his 1977 report and Figure 17.18 here. This would result in the reversal of Hed Mound Periods III and IV as depicted in panels 3 and 4 of Figure 7 of that report and in Figures $17.17 \mathrm{~A}$ and $17.17 \mathrm{~B}$ here.

House P in the swamp and Houses 1-3 of Periods V-VII on Hed Mound are large enough structures for their excavators to interpret them as providing accommodation for people and pigs under the one roof in late Phase 5, in the way described in the ethnographic literature for the upper Wahgi. If features 37-39 of former Harris Period IV are really evidence of an earlier house, this would also have the size and shape to be interpreted as a structure for both pigs and people at an earlier stage of Phase 5.

We once thought that we had direct evidence of pig early in Phase 5 at Kuk, supplied by the discovery of pig bone in old subphases of Wai's Baret at two different locations: where it is crossed by drains of E-W Rd 1 (see section B in Figs 15.2 and 15.7) and of E-W Rd 3 some $650 \mathrm{~m}$ downstream. The bone at the first location was the back of a skull, allowing the specimen to be identified ${ }^{4}$ as Sus papuensis, a stabilised hybrid between $S$. (cf. scrofa) vittatus of the Malay peninsula, Sumatra and Java and S. celebensis of Sulawesi (on which see Groves 1981: 64-66). The precise stratigraphic location of the find is unknown since it had fallen from the drain wall with slumping of Wai's Baret infill, but it was adjudged early because of the type of material in which it was included. However, it gave a calibrated radiocarbon age of AD 1670 or less, ${ }^{5}$ which is Phase 6 in terms of the Kuk sequence. The second find, of two pig teeth from the basal fill of Wai's, is stratigraphically more secure. However, the calibrated age of the teeth is between AD 1490 and $1650,{ }^{6}$ or late Phase 5. This raises the possibility of downward movement of small objects in the stratigraphy, which has been a major problem for the dating of pig teeth from highlands rockshelters (Hedges et al. 1995: 428). As things stand, however, all directly dated highlands pig bone samples, as reported by Hedges et al. (1995: 428) and here, have returned dates of later than 400 radiocarbon years BP, roughly after AD $1450 .^{7}$

\footnotetext{
4 By Colin Groves, School of Archaeology and Anthropology, The Australian National University.

5 Calibration of KIA-35647, 135 \pm 25 BP, at two standard deviations; courtesy of Keith Dobney (now Department of Archaeology, University of Aberdeen), who sponsored the dating.

6 Calibration of Wk-28559, 302 \pm 30 BP, at two standard deviations; courtesy of Elizabeth Matisoo-Smith (now Department of Anatomy and Structural Biology, Otago School of Medical Sciences, University of Otago), who sponsored the dating.

7 There is a single date for a directly dated pig bone from Indonesian New Guinea in the top level of Kria Cave on the Bird's Head, associated with the first pottery as well as the first pig at the site (Pasveer 2004: 57 and Table 3.2). The date in question is OZE 542, reported as $>1840 \pm 40$ radiocarbon years BP because of suspected younger contamination. We are told (Pasveer 2004: 654, fn 1) that this should be regarded as a minimum age.
} 
Yet, as we saw in Chapter 14, pigs were present in the south Papuan lowlands by around 2500 years ago, with the potential to move or be moved into the interior. Particularly apposite for the upper Wahgi from this point of view is the site of Emo at the delta of the Kikori River at the Gulf of Papua, where definite pig bones have been found in association with pottery dating around 1600 years ago, and probable pig bones 200 years earlier (David et al. 2010: 49, 51). This is the period of Kuk Phase 4, which saw the development of the trade and exchange of axes made of stone from specialised quarries in the middle Wahgi and Jimi Valleys that was characteristic of the region at European arrival (see Chapter 14, section 'Kuk as a Phase 4 "hotspot"?' and Chapter 21, 'Ground axes and axe quarries' and following sections). As we shall see in Chapter 16, section 'Dating Phase 6 at Kuk', such axes have been found in the middle Kikori River region above the delta, contemporary with Kuk Phase 6 in the upper Wahgi, which was initiated by the arrival and adoption of the sweet potato. The question of the sweet potato's time and mode of entry into New Guinea and its spread into the highlands is discussed below and in Chapter 16. By this time, as we saw in the previous paragraph, pigs had already made their appearance in the highlands.

\section{Interpretation}

\section{Phases 3, 4 and 5 compared}

Interpretations of the Phase 5 evidence are made difficult by the absence of any direct evidence for the crops being grown in wetlands at this time. However, the difference in ditch morphology between Phases 4 and 5 suggests a change in agricultural technology and a switch from taro to other crops. In Phase 4, taro was cultivated with the digging stick, a tool used both to excavate the slot-like field ditches and also, by ethnographic analogy, to make planting holes. In contrast, as we have said, the flat-bottomed ditches of Phase 5 indicate the use of a spade of the paddleshaped type, of which an example was excavated from a Phase 5 ditch. The increased volume of soil that was produced suggests an interest by the cultivator in soil tillage and the raising of beds for planting a different suite of crops. Whereas Phase 4 ditches are infilled with silty clay containing some fine soil aggregates, the fill in Phase 5 is a fine earth derived from garden soils that has had time to settle and compact.

In fact, Phase 5 ditches bear a stronger resemblance to late Phase 3 ditches than to those of the intervening Phase 4 (Fig. 15.14). Measurements taken from the cross-sections of samples of field ditches belonging to each phase reveal that late Phase 3 ditches have an average width of 341 $\mathrm{mm}$ at the base and $905 \mathrm{~mm}$ at the top of black clay, whereas Phase 5 ditches have equivalent dimensions of $406 \mathrm{~mm}$ and $679 \mathrm{~mm}$ respectively. In both cases, therefore, the Phase 3 and 5 field ditches are significantly wider features generating much more ditch spoil than Phase 4 ditches, whose average width is only $94 \mathrm{~mm}$ near the base and $474 \mathrm{~mm}$ at the top of black clay. When we measure their depth below black clay level, Phase 4 ditches have a similar modal depth to Phase 5 ditches, in both cases 300-400 mm, whereas those from Phase 3 appear to be somewhat deeper (mode 500-600 mm). However, the Phase 3 sample size is too small for us to draw firm conclusions about their depth being significantly different. 


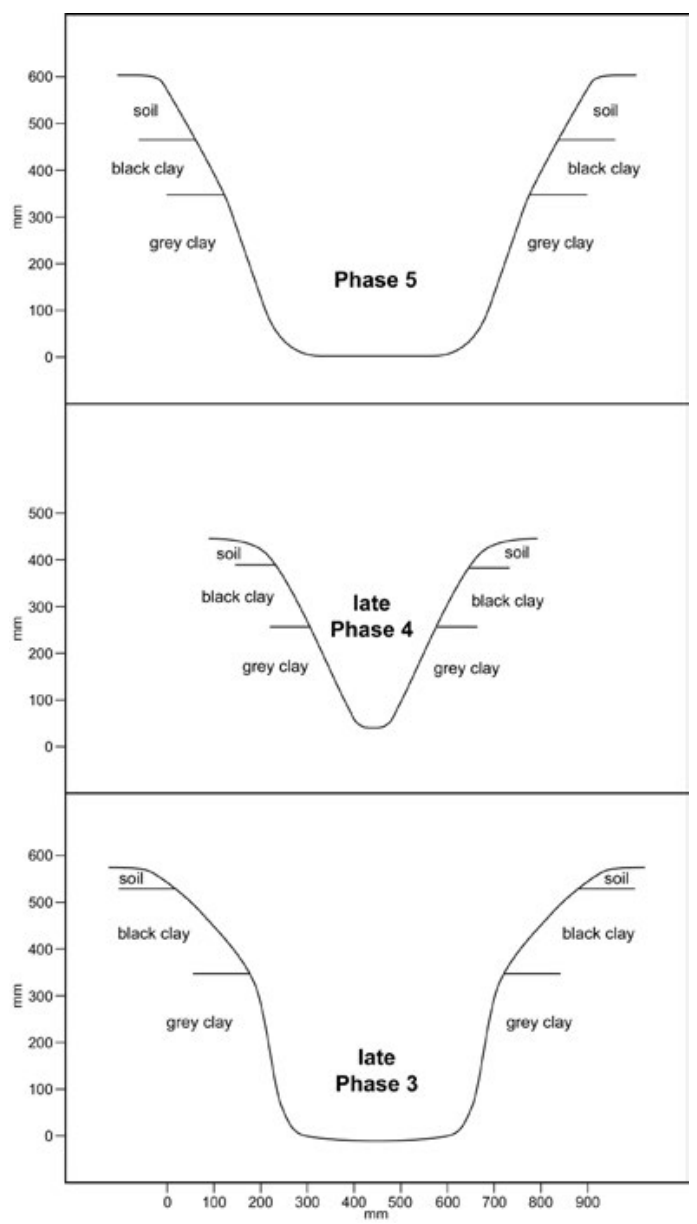

Figure 15.14 The 'typical' ditch in late Phase 3, Phase 4 and Phase 5.

For Phase 4 the cross-section is based on modal rather than mean widths and depths to avoid the distortion of the mean that results from a skewed frequency distribution (see Figs 15.11 and 15.12). For Phase 3 and Phase 5 average statistics were used because means are close to modes and therefore can be used to represent the 'typical' shape of a ditch. We interpret the different size and shape of Phase 4 field ditches compared with those of either Phase 3 or Phase 5 as resulting from the cultivators using a different tool in order to cultivate a different crop. In Phase 4, heavy digging sticks, not spades, were used in order to grow taro rather than the yams, sugarcane and bananas that, we believe, dominated Phase 3 and Phase 5 cultivation.

Source: Drawing by Philip Stickler based on measurements and calculations by Tim Bayliss-Smith on field data from the Kuk archive, 1972-76.
The more plentiful supply of soil in Phase 5 became a planting medium on fields or beds ('gardens'). The fields themselves tended to become larger and more elongated during the course of the phase. On these rectangular beds, various forms of cultivation would have been feasible and, although direct evidence is lacking, plants could have included yam, winged bean, banana and sugarcane. Taro, with its vulnerability to pest damage in grassland areas, had probably become a minor crop. Phase 5 ditches have also been found outside wetlands, in grid patterns antedating Tibito Tephra, for example at Mugumamp Ridge in the North Wahgi Swamp (Harris and Hughes 1978: 442-443) and at Kuk itself (Gorecki 1982: 283-284). It has been suggested that the cultivation of raised beds using ditch spoil was a practice that was initially developed in the wetlands of early Phase 5 and later transferred to the dryland sphere (Golson 1977a: 629630; 1982: 119).

Alternatively, it is possible that Phase 5 represents an expansion into wetlands of an already established dryland system of soil tillage and raised-bed cultivation. At present, there is no evidence to indicate in which environment the Phase 5 technology of ditches and raised beds was first used, whether in drylands or wetlands, although the latter scenario seems more plausible. After reviewing the dating evidence for the onset of Phase 5 in an early section of this chapter, we concluded that it took place during the date range between AD 980 and 1410 and probably in the third quartile of this, around AD 1250. Its onset may have been in the context of El Niño droughts triggered by the huge volcanic eruption on Lombok in $\mathrm{AD} 1257$, as previously discussed above. If so, then Phase 5 lasted about 400 years, providing an extended timeframe for lessons to be learnt in the swamp and later transferred to the dryland sector.

We suggest that the foregoing combination of circumstances-substantial ditches as the source of soil for raised gardens in dryland as well as wetland contexts, together with the paddle-shaped spades associated with their construction-indicates that taro was no 
longer the major crop that it had been in Phase 4 times. As discussed above, the interval between the end of Phase 4 and the start of Phase 5 was occupied by a period of warmer and more stable climate. We believe that in this period the changes in agricultural practice took place that characterise Kuk Phase 5, initiating a process of intensification of which both Dioscorea esculenta and pig may have been an integral part.

As previously discussed, pigs were present in the southern Papuan lowlands before the beginning of Phase 4 in the highlands, when there is evidence for the development of systems of trade and exchange in which the pig would have had a part to play, had it been there to do so. It also seems likely that the lesser yam (Dioscorea esculenta) moved into southern Papua following the Lapita settlement of Austronesian speakers there in the first half of the third millennium BP (see Chapter 14, section 'Phase 4 in its wider context'), finding its way into the highlands in the favourable climate of the Mediaeval Warm Period. Mike Bourke (pers. comm., 2013) says that the modern highlands climate is too cool for the lesser yam to thrive and points out (Table 4.1, note 3) that it is not common above $900 \mathrm{~m}$. Nonetheless, as we shall see in Chapter 16, section 'An overview of the evidence', a large tuber fragment excavated from a Phase 6 house site at Kuk proved to be from lesser yam, not sweet potato, as expected.

At lower altitudes, D. esculenta can be a major staple supporting high population densities, as in the southern foothills of East Sepik Province (Swadling and Hide 2005: 314-317). Yams are also important in some grassland areas of the eastern highlands, as at Okapa (1600-1800 m), but here the greater yam, D. alata, is the important crop. Boyd (1975: 109-115) found 53 named varieties of yams growing in Okapa gardens, of which 43 were D. alata, six D. bulbifera, two $D$. pentaphylla and one each D. nummularia and D. esculenta. By the 1970 s, yams were only a supplementary crop in the Mount Hagen area with sweet potato increasingly predominant (about 50 varieties). Nonetheless, there were still about 25-30 varieties of yams in cultivation, mostly $D$. alata with a few $D$. esculenta and $D$. bulbifera. By comparison, there were 31 varieties of taro still being cultivated, 22 of sugarcane and a remarkable 48 varieties of winged bean, Psophocarpus tetragonolobus (Powell et al. 1975: 15-27).

In Chapter 14, we reviewed evidence of severe yield losses from Papuana beetle attack for farmers attempting taro cultivation in grassland areas of the highlands. This is matched by the archaeological evidence from Phases 4 and 5 at Kuk, which suggests a change in cultivation practices as taro cultivation became increasingly problematic in the largely deforested upper Wahgi Valley. We have identified other crops, greater yam Dioscorea alata in particular, that could have formed the basis for a new cropping system in Kuk Swamp in Phase 5. Taro remained the staple for those with access to forest land for new swiddens, but in deforested areas such as the Wahgi taro could be supplemented with an alternative agricultural system in drained wetlands based on yams, bananas, winged beans and sugarcane. We hypothesise that this system was maintained at Kuk throughout Phase 5 until the sweet potato revolution of the last three centuries created a new set of opportunities, which we discuss as Phase 6 in Chapter 16.

\section{Possible reasons for Phase 5 drainage}

Whatever the date of the start of Phase 5 and the appearance of pigs at Kuk, there can be no doubt that by then the replacement of forest by secondary growth and grassland due to clearance for agriculture was well advanced in the Wahgi region (see the 'Mid to late Holocene' section of Chapter 9). With the availability of bush resources much reduced, pigs would have been a welcome replacement as a source of protein. However, because their opportunity to forage would have been limited in conditions of deforestation, there would have been need for them to be regularly fed from garden produce and for food gardens to be protected from them (see the 'House timbers and fence stakes' section of Chapter 19). As a result, pig-keeping would 
have been expensive in terms of the labour (mainly women's) invested in it, with pig ownership becoming a symbol of wealth and influence, as it has been in highlands societies of recent times. In these circumstances, pigs would have had a part to play in systems of exchange (cf. Golson 1982: 123-130; Golson and Gardner 1990: 398-405).

In Chapter 14, section 'Kuk as a Phase 4 "hotspot"?', we suggested that such systems of exchange had begun to develop in the highlands during Phase 4, characterised by the distribution of axes of valued quarry stone. The incorporation of pigs into such systems might have been the trigger for the inauguration of Phase 5 drainage to support and extend their role in ceremonial exchange.

How far was the renewal of swamp drainage in Phase 5 also driven by a crisis in dryland cultivation ('push' factors), rather than by the incentive of surplus production from the wetlands ('pull' factors)? As discussed earlier in this chapter, there is some evidence that the period before about AD 1250 was a time of warmer and more stable climate. Reconstructions of sea-surface temperatures based on ocean cores from Sulawesi confirm that the whole region experienced cooler temperatures between about AD 400 and 950 than during much of the Mediaeval Warm Period that followed (Oppo, Rosenthal and Linsley 2009: 1114). Sea-surface temperatures decrease during El Niño events, so that the regional cooling of the Little Ice Age after AD 1200 could reflect a more intense El Niño-Southern Oscillation (Conroy et al. 2008; Oppo, Rosenthal and Linsley 2009) and a southwards shift of the Intertropical Convergence Zone (Buckley et al. 2010).

If the New Guinea highlands began to experience more frequent and more severe ENSO droughts around $\mathrm{AD} 1250$, then the greater security of production offered by wetlands sites such as Kuk would have been an additional reason for undertaking large-scale drainage. Parallel changes have been suggested for the Pacific islands by Patrick Nunn (2007; Nunn and Hunter-Anderson 2011), who sees evidence for an impact on settlement and agriculture following a shift in climate and a fall in sea level after AD 1300. In the Sigatoka Valley in Fiji, for example, episodic droughts and floods associated with ENSO events may have intensified the competition for resources and led to increased warfare during the period AD 1500-1700 (Field 2004). Did drought in New Guinea provide a comparable stimulus towards wetland drainage? An important step towards testing this hypothesis would be to establish with greater accuracy the date when Phase 5 began at Kuk and other sites.

There is evidence from elsewhere of Asian monsoon failure and resulting 'megadroughts' (Cook et al. 2010) that correlates with the Phase 5 chronology. Studies of tree-ring widths at Bidoup Nui Ba in Vietnam and of reservoir sediments near Angkor Wat in Cambodia have confirmed that intense droughts were experienced in southeast Asia in the mid-13th century. These were followed by the well-known Angkor Drought periods of AD 1345-65 and 1401-25 (Buckley et al. 2010: 6750; Day et al. 2012: 1048). Just as failure of the hydraulic network that sustained Angkor is now seen as contributing to its collapse, perhaps there is a parallel in New Guinea. It is tempting to see the onset of this period of increased frequency and intensity of drought as a regional phenomenon and as the trigger that initiated Phase 5 of drainage at Kuk. Can we also see the recurrence of drought problems in dryland agriculture as explaining the long duration of Phase 5 during the Little Ice Age period? Is it conceivable that the two Angkor Droughts (mid-14th century and early 15th century) are reflected in the evidence of Kuk Phase 5 major disposal channels and field ditches? Precise dating of the features is not possible, but the Kuk evidence suggests that subsequent to their initiation the channels and ditches of early Phase 5 were redug at least twice, enabling Kuk Swamp to continue in agricultural use. 


\section{Reasons for disintensification}

Just as the network of minor ditches declined towards the end of Phase 5 (see above, 'Ditch networks and field systems'), so the disposal channels suffered some degree of neglect. We have already outlined the evidence for less maintenance work being carried out on the major disposal channel and one of its tributaries (see Figs 15.7 and 15.8). It is plausible to envisage a causal link between this declining investment in the major disposal channels and an increasing importance of the dryland sphere and products from that sphere, together with impacts on the wetland drainage system from erosion in the dryland catchments. If so, then one explanation for this declining investment is that by the end of Phase 5 (and especially afterwards, in Phase 6), Wahgi society became more and more focused on dryland tillage and raised-bed cultivation, pig husbandry and regional exchange. Perhaps in the wetland sphere, therefore, some increased crop losses due to flooding became acceptable in late Phase 5.

A strong focus on the dryland sphere of production was indeed the situation that prevailed in 1933, at the very end of prehistory, at a time when the wetlands in the Wahgi Valley had been largely abandoned. At contact the collective efforts of men, coordinated by influential big-men, were very largely focused on exchange activities, interrupted by spasmodic warfare. Strong gender divisions characterised Wahgi society and women's agricultural activities concentrated almost entirely on the dryland production of sweet potato (Strathern 1971: 8-10). Wetland drainage on any scale was no longer feasible partly because the social capital no longer existed that would have mobilised gangs of men to undertake the digging of major disposal channels.

Transposing these insights back in time, it is tempting to see the reasons for wetland abandonment after Tibito Tephra in the late Phase 5 disintensification process. Is it possible that an early arrival in the Wahgi Valley of the sweet potato was responsible for these changes? Answering this question would be easier if we could date more accurately the changes that occurred late in Phase 5, before its termination possibly in the AD 1660s. The earlier the decline in wetland use began, the more unlikely it is that sweet potato was implicated, given that it was a European introduction into Southeast Asia in the early AD 1500s and had to be transferred eastwards along traditional routes of trade and exchange. Partly on the basis of linguistic evidence, Pamela Swadling (1996: 155-165, 282) has argued for its transport from the Moluccas to the southern New Guinea coast by traders of Seram Laut, who from around AD 1645 to 1790 had contact with the Trans-Fly region. From here, the plant spread inland of Kikori into the Erave area of present-day Southern Highlands Province and thence into the upper Wahgi Valley, likely following the route by which pearl shells from Torres Strait were traded into the highlands (Swadling 1996: 156, 165; see Chapter 16, section 'Dating Phase 6 at Kuk'). A date of AD 1645 is, of course, possibly fewer than 20 years before the fall of Tibito Tephra and the end of Phase 5, and not long before the beginning of its successor, Phase 6 .

Phase 6, as we shall see in Chapter 16, is a period when no agricultural drainage of any consequence was done at Kuk in the deeper parts of the swamp north and east of Wai's and Simon's Barets. By looking at the history of Phase 5 agricultural drainage in this part of the swamp, it should be possible to judge whether the arrival of the sweet potato was the decisive factor in the end of wetland cultivation at Kuk. The evidence for that history is provided by the stratigraphic relationships of Phase 5 garden ditches in the walls of modern drains to the visible time horizons provided in those walls by preserved remnants of two volcanic ashes, Kenta tephra, which fell at an early stage of Phase 5, and Tibito Tephra, which saw its end. Kenta is of limited value for this purpose since it is of rare occurrence. Tibito is much more frequent in appearance and we can use it as a rough measure of relative age for the ditches with which it is associated. Thus a ditch is early Phase 5 if the tephra lies level at the top of or above its fill, mid-Phase 5 if it sits in the middle to upper fill, late Phase 5 if it is at the bottom of the fill and Phase 6, of course, if the ditch cuts through it. Since we are particularly concerned with late Phase 5 ditches, we 
divide these into three rough categories: 'latest' when the base of the tephra is $0-20 \mathrm{~mm}$ above the base of the ditch; 'late' when it is between $20-60 \mathrm{~mm}$ above the base; and 'lateish' when it is 60-100 $\mathrm{mm}$ above.

Not every drain that we dug in the deep swamp east and north of Simon's and Wai's Barets was dug and recorded with the problems of Phase 5 in mind. As a result, we can only do the analysis of Phase 5 ditching described below using six of the 11 drains dug east of Simon's Baret in blocks A1012 and seven of the 14 drains dug east of Wai's and Simon's Barets in blocks B10-12 (see Fig. 15.4). In the 13 drains that we are using, which are represented in all six blocks, ditches associated with Kenta and Tibito were recorded and could be allocated to the categories described in the last paragraph. There is a total of 170 Phase 5 ditches, of which 122 or just under 72 per cent are in the early to mid category, with 48 or just over 28 per cent in the late. The single drains $\mathrm{C} 12 \mathrm{e} / \mathrm{f}$ and D9g/h (see Fig. 15.4) are eligible for inclusion. The former has a count of 17 Phase 5 ditches, of which 12 (70 per cent) are in the early to middle category and five $(30$ cent) are late. Of the 19 ditches in drain D9g/h, 14 or 74 per cent are early to middle period and five or 26 per cent are late.

We can be sure that the counts for ditches of the early and middle periods are an underestimate, given the destruction or compromising of evidence by later digging. On the other hand, the late category of ditches as defined must belong to a relatively short period before the fall of Tibito Tephra, a period far shorter than that covering the middle and early categories that extend back to the beginning of Phase 5 before the fall of Kenta. This is certain despite the unsatisfactory dating of the Kenta ashfall, as discussed above: earlier than the overlying peat, whose radiocarbon date calibrates within the age range AD 1270-1640, and between AD 1340 and 1460 by rate of sedimentation. We can summarise by saying that wetland agriculture at Kuk in late Phase 5 , while the subject of some neglect, was by no means in crisis (see above, 'Ditch networks and field systems'). No other conclusion seems valid, especially when we consider that although 72 per cent of the 170 ditches in the 13 drains of the A and B blocks belong to the early to middle period, as many as 28 per cent were dug in the late period despite it being much shorter in duration. Indeed, of the 48 late period ditches present in the A and B block drains under analysis, at least 11 belong to the latest subphase, with Tibito Tephra no more than $20 \mathrm{~mm}$ above the base of the ditches in question. These cases are well distributed across the area with which we are concerned (see Fig. 15.4)— two in drain A11a/b, four in A11f/g, one in B10e/f, one in B11a/b, two in $\mathrm{B} 11 \mathrm{~d} / \mathrm{e}$ and one in B12c/d. In addition, there is one certain and one possible example in drain $\mathrm{C} 12 \mathrm{e} / \mathrm{f}$ and two certain ones in drain D9g/h. All these ditches were open at the fall of Tibito Tephra, but were they operating as part of a system? Certainly they were never used again.

There are a number of scenarios for a decline of wetland agriculture at the time of the Tibito ashfall and the appearance of the sweet potato. One is the fragility of the structures required for organising collective work projects like major ditch maintenance and their consequent vulnerability to disruption in circumstances of social change plausibly initiated by the appearance of the sweet potato.

An alternative view would see Phase 5 society in the Wahgi as one already marked by social stratification, big-men leadership and gender inequality (Golson 1982). The disintensification of wetland landuse during this phase would not reflect any fragility in organisational structures, but instead would signal the growing success of dryland agriculture based on soil tillage, ditching for raised-bed cultivation, surplus production of yams and women's labour. Whereas at the start of Phase 5 the wetlands still offered significant incentives for surplus, wealth and prestige, by the 17 th century dryland agriculture was more productive-and of course became still more so after the boost to fertility provided first of all by Tibito Tephra and later by the sweet potato. In this dynamic society of escalating wealth, exchange and social inequality, political instabilities and intergroup warfare provided another reason for wetland agriculture to become less attractive, because of the increased risk of disruption to the major disposal channels. 
Disease is another possibility. Paul Gorecki (1979a) has reconstructed the patterns of population movement that had led to the depopulation of most of the valley flats in the Wahgi, Baiyer and Nebilyer Valleys by the 20th century. He argues that if, hypothetically, one repopulates the valley flats with those tribes that had relocated to other valleys nearby, such as the Jimi, Kambia and Kaugel, then 'one gets a picture of a dense population living in and around the swamps prior to the introduction of the sweet potato some three hundred years ago' (Gorecki 1979a: 104). The abandonment of the valley floors, he suggests, came about as a result of the arrival of malaria, probably following traditional trade routes and apparently postdating the appearance of the sweet potato (Gorecki 1979a: 104-105). Nelson (1971: 206-207, 208-209) makes many of the same points about the inhabitants of the Nebilyer Valley immediately southwest of the upper Wahgi and their contacts with the people of the upper Purari drainage to the south, though he proposed a now unacceptable younger date for the events in question (on which see Blong 1975).

\section{Conclusion}

It may in future become possible to put Phase 5 at Kuk into some wider context of highlands prehistory, but at present the sparse nature of the evidence available beyond Kuk makes comparisons very difficult. By various lines of evidence, we have argued that this phase of drainage probably began in the later part of the period between AD 980 and 1410, perhaps soon after 1250 , and did so for reasons that are unclear but probably related to a deteriorating environment for dryland production. Access to forests had become more difficult with the spread of grasslands, so that opportunities for hunting and gathering would have declined. Dryland crop production was also growing more difficult on degraded grassland soils that were subject to more frequent drought hazards from El Niño events. At the same time, we envisage a continuing expansion of pig husbandry and regional exchange, stimulated by what had become a highly differentiated mosaic of different environments and societies, integrated by exchange relationships that extended across the highlands and perhaps beyond. Therefore, both 'push' and 'pull' factors could be implicated, with subsistence crisis and incentives for surplus production, wealth and prestige lying behind this new phase of wetland reclamation.

What is clear is that Phase 5 was very different in agricultural technology from Phase 4, even if in broad hydrological terms the two phases functioned similarly. The use of spades, the construction of raised beds with soil tillage and a predominance of dryland crops like banana, yam and winged bean rather than taro seem likely. We envisage a social landscape of intensive cultivation based on growing social stratification extending far and wide across the upper Wahgi Valley and beyond.

The end of Phase 5 at Kuk, after the fall of Tibito Tephra and the Time of Darkness by which it is remembered, was sudden, but abandonment of swamp cultivation was short-lived, as discussed in the next chapter on Phase 6. The evidence suggests that Phase 5 was at its peak in its early subphase, in terms of coordination and intensity of effort. In the late subphase, sometime before Tibito Tephra fell, possibly in the AD 1660s, there is evidence of some decline in drainage effort. Whether the beginning of sweet potato cultivation was responsible or alternatively whether we should invoke purely sociopolitical factors — escalating warfare, disease, gender divisions in society, alternative male projects connected to widening exchange activity-is unclear at present. It may be that the important factor was the adoption in the dryland sphere of swampland techniques of ditching and raising garden beds, which became characteristic features of dryland sweet potato production in Phase 6. It was in that phase that the effects on wetland drainage caused by the sweet potato become apparent. Its coming unleashed a revolution in subsistence, but the evidence from Kuk shows that during Phase 5 the agricultural technology and the social relations of production necessary for this dramatic change were put in place. 
This text is taken from Ten Thousand Years of Cultivation at Kuk Swamp in the Highlands of Papua New Guinea, edited by Jack Golson, Tim Denham, Philip Hughes, Pamela Swadling and John Muke, published 2017 by ANU Press, The Australian National University, Canberra, Australia. 